\title{
The health and economic benefits of the global programme to eliminate lymphatic filariasis (2000-2014)
}

Hugo C. Turner ${ }^{1,2^{*}}$, Alison A. Bettis ${ }^{1,2}$, Brian K. Chu ${ }^{3}$ Deborah A. McFarland ${ }^{4}$, Pamela J. Hooper ${ }^{3}$, Eric A. Ottesen ${ }^{3}$ and Mark H. Bradley ${ }^{5}$

\begin{abstract}
Background: Lymphatic filariasis (LF), also known as elephantiasis, is a neglected tropical disease (NTD) targeted for elimination through a Global Programme to Eliminate LF (GPELF). Between 2000 and 2014, the GPELF has delivered 5.6 billion treatments to over 763 million people. Updating the estimated health and economic benefits of this significant achievement is important in justifying the resources and investment needed for eliminating LF.

Method: We combined previously established models to estimate the number of clinical manifestations and disability-adjusted life years (DALYs) averted from three benefit cohorts (those protected from acquiring infection, those with subclinical morbidity prevented from progressing and those with clinical disease alleviated). The economic savings associated with this disease prevention was then analysed in the context of prevented medical expenses incurred by LF clinical patients, potential income loss through lost-labour, and prevented costs to the health system to care for affected individuals. The indirect cost estimates were calculated using the human capital approach. A combination of four wage sources was used to estimate the fair market value of time for an agricultural worker with LF infection (to ensure a conservative estimate, the lowest wage value was used).

Results: We projected that due to the first 15 years of the GPELF 36 million clinical cases and 175 (116-250) million DALYS will potentially be averted. It was estimated that due to this notable health impact, US\$100.5 billion will potentially be saved over the lifetimes of the benefit cohorts. This total amount results from summing the medical expenses incurred by LF patients (US\$3 billion), potential income loss (US\$94 billion), and costs to the health system (US\$3.5 billion) that were projected to be prevented. The results were subjected to sensitivity analysis and were most sensitive to the assumed percentage of work hours lost for those suffering from chronic disease (changing the total economic benefit between US\$69.30-150.7 billion).
\end{abstract}

Conclusions: Despite the limitations of any such analysis, this study identifies substantial health and economic benefits that have resulted from the first 15 years of the GPELF, and it highlights the value and importance of continued investment in the GPELF.

Keywords: Lymphatic filariasis, DALYs averted, Health impact, Economic impact, GPELF, Programme evaluation

\footnotetext{
* Correspondence: hugo.turner@imperial.ac.uk

'London Centre for Neglected Tropical Disease Research, London, UK

${ }^{2}$ Department of Infectious Disease Epidemiology, School of Public Health,

Faculty of Medicine, St Marys Campus, Imperial College London, Norfolk

Place, London W2 1 PG, UK

Full list of author information is available at the end of the article
} 


\section{Multilingual abstracts}

Please see Additional file 1 for translations of the abstract into the five official working languages of the United Nations.

\section{Background}

Lymphatic filariasis (LF), also known as elephantiasis, is a neglected tropical disease (NTD) now targeted for elimination through the Global Programme to Eliminate LF (GPELF). When this Programme began in 2000, there were 1.3 billion people in 73 endemic countries at-risk of LF. It was estimated that approximately 120 million people were infected with LF, of which 40 million were suffering from overt clinical disease - manifested as painful severe swelling due to lymphedema (an accumulation of lymphatic fluid generally in the limbs) and hydrocele (fluid accumulation in the scrotal sac) $[1,2]$.

As a public health problem, LF is treated with preventative chemotherapy (Table 1) using a combination of either albendazole and ivermectin (in areas co-endemic with onchocerciasis) or albendazole and diethylcarbamazine (DEC) elsewhere. To achieve its elimination goals, the GPELF guides endemic countries in implementing annual, singledose mass drug administration (MDA) against LF using either of these two drug regimens. The MDA strategy is unique in targeting all people of all ages in the endemic population who are eligible to take these safe and effective

\section{Table 1 Glossary}

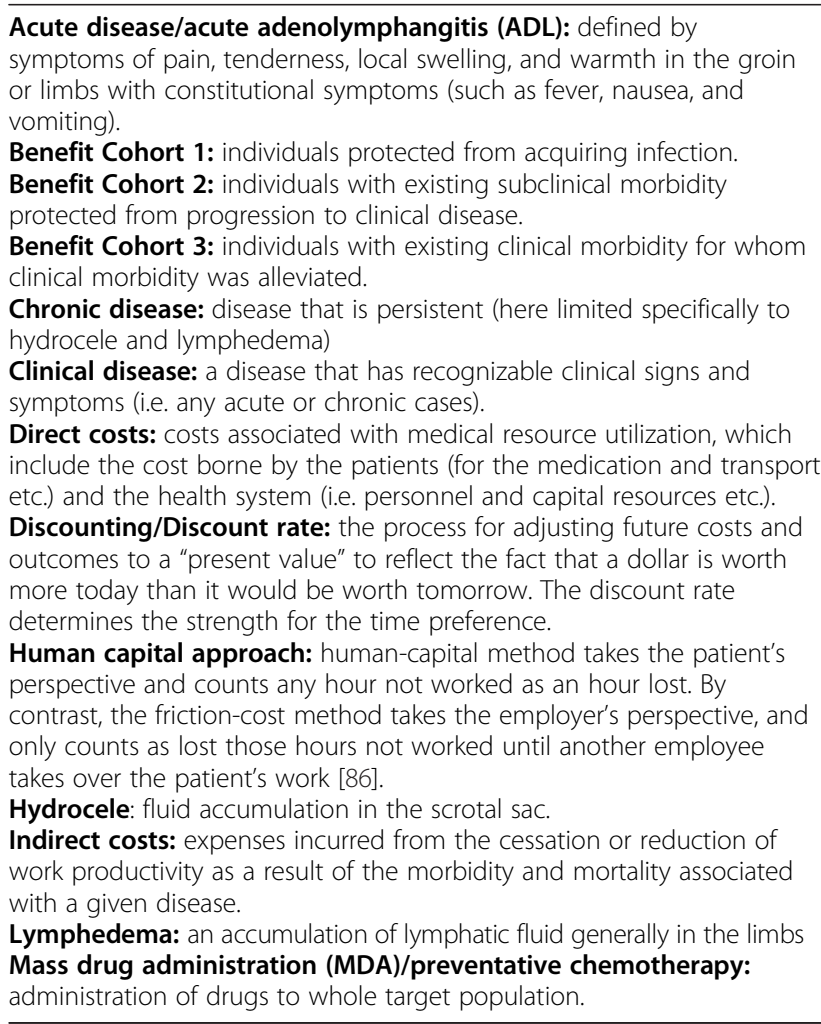

medicines (Table 1). This strategy has been shown to be feasible, inexpensive and cost-effective [2, 3], principally because the drugs used are donated by pharmaceutical partners.

Over the first eight operational years of the GPELF (2000-2007), more than 1.9 billion MDA treatments were administered to approximately 570 million individuals in 48 countries. This notable programmatic achievement resulted in a significant impact on the health of endemic populations [2]. A previous analysis by Chu et al. [4] estimated that due to GPELF activities between 2000 and 2007, over US\$23 billion of economic benefits would be accrued by individuals and the health systems in MDAtreated areas (over the lifetime of those treated).

Since 2007, more countries have started MDA and others have expanded their treatment coverage (Fig. 1). This was made possible largely by new resource commitments for programme implementation from bilateral donors (especially DFID and USAID), the Bill \& Melinda Gates Foundation, and other non-governmental development organizations (NGDOs) - funds that were needed to deliver the increased drug contributions from industry partners (initially GSK and Merck \& Co, and more recently Eisai).

Assessment of the economic and health impact of the GPELF was first made after 8 years of programme activity $[2,4]$, but now given both the expansion of the programme during its subsequent seven years and the new strategies available for modelling its impact, the present manuscript aims to provide updated estimates of the health and economic benefits of the GPELF from 2000 to 2014.

\section{Methods}

GPELF - numbers at risk, and numbers treated

As seen in Table 2, since 2007, the programme has expanded to a further 13 countries and delivered over 3.68 billion more treatments (Table 2). Therefore, the number of people at-risk of infection and the numbers treated that were reported by $\mathrm{Chu}$ et al. [4] could be updated from the World Health Organisation (WHO) PCT databank [5] and the 2014 GPELF progress report [6]. The numbers of people at-risk of infection were estimated from data resulting from new mapping activities, and the numbers and populations treated, from countries' annual reports to WHO and the drug donation programmes (summarized in the PCT databank [5]).

\section{Epidemiological model and assumptions}

Based on previous analyses [2, 4], the following key assumptions were made (Fig. 2 and Table 3):

- Before control, $10 \%$ of the at-risk population would be infected with LF, and this ratio remains constant in the absence of MDA [2]. 

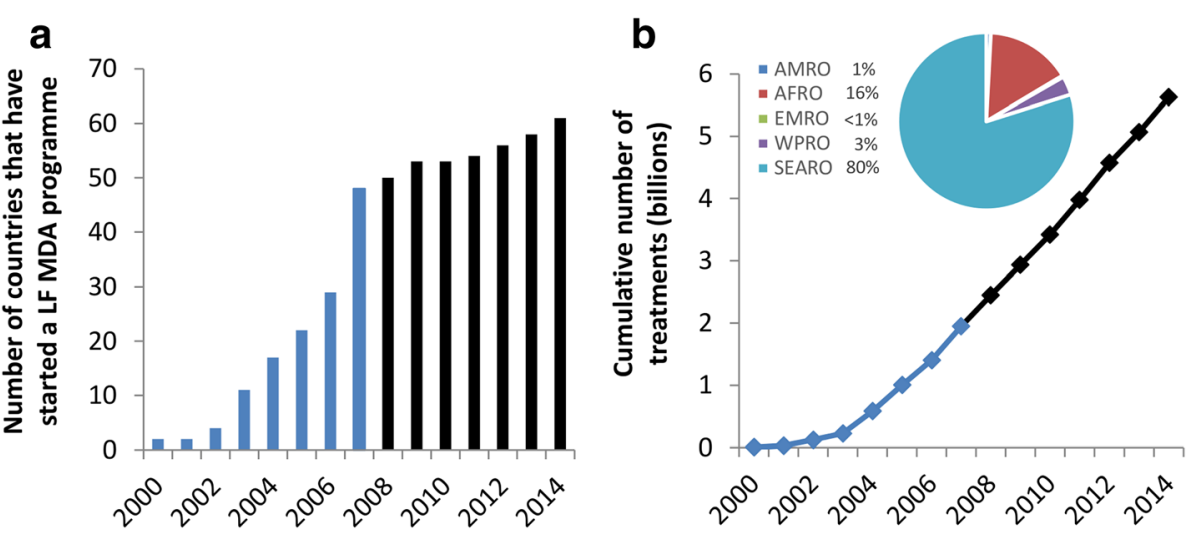

Fig. 1 The number of countries that have started a LF MDA programme (a) and the cumulative number of treatments (b) provided by the GPELF over time. Data from the PCT databank [5]. Values in black indicate data provided after the timeframe of the previous analyses (2000-2007) [2, 4]. Insert in panel $\mathbf{b}$ illustrates the proportion of the cumulative number of treatments (2000-2014) in each of the different WHO regions (AMRO Region of the Americas, AFRO African Region, EMRO Eastern Mediterranean Region, WPRO Western Pacific Region, SEARO South-East Asia Region)

- One-third of those with LF infections would have clinical disease $(3.33 \%$ of the total at-risk population).

- The other two-thirds of individuals infected with LF actually have subclinical morbidity [1]; half of these cases would progress to overt clinical disease in their lifetimes [2].

- Cases of clinical disease occur in the following proportion: $62.5 \%$ hydrocele, $37.5 \%$ lymphedema [7]. It was assumed that the relative frequency of the clinical disease presentations remains stable among those infected individuals.

For LF, acute disease refers to recurring attacks of acute adenolymphangitis (ADL), defined by symptoms of pain, tenderness, local swelling, and warmth in the groin or limbs with constitutional symptoms (such as fever, nausea, and vomiting) [8-10]. It was assumed that these episodes last on average 4 days [8, 10-17]. Seventy percent of hydrocele and $95 \%$ lymphedema patients were assumed to experience ADL episodes, with an average of two and four episodes per year respectively [8, 10-17]. These assumptions were varied in the sensitivity analysis.

\section{Calculating the health impact of the GPELF Benefit Cohort Populations and the impact of treatment} For this analysis, the only individuals assumed to be incurring a health (and later, economic) burden due to LF were those with clinical disease. Consequently, three broad groups of individuals were recognized to have benefits

Table 2 GPELF MDA treatments (2000-2014)

\begin{tabular}{|c|c|c|c|}
\hline WHO region & GPELF countries (2000-2014) & $\begin{array}{l}\text { Pre-control number at-risk } \\
\text { of infection (millions) }\end{array}$ & $\begin{array}{l}\text { Minimum number treated } \\
\text { 2000-2014 (millions) }\end{array}$ \\
\hline AMRO & Brazil, Dominican Republic, Guyana, Haiti. & 14 & 10 \\
\hline AFRO & $\begin{array}{l}\text { Benin, Burkina Faso, Cameroon, Central African Republic, Comoros, Congo, } \\
\text { Côte d'Ivoire, Democratic Republic of Congo, Ethiopia, Ghana, Guinea, } \\
\text { Guinea-Bissau, Kenya, Liberia, Madagascar, Malawi, Mali, Mozambique, } \\
\text { Niger, Nigeria, Senegal, Sierra Leone, Tanzania (incl. Zanzibar), } \\
\text { Togo, Uganda. }\end{array}$ & 425 & 191 \\
\hline EMRO & Egypt, Sudan Yemen. & 23 & 3 \\
\hline WPRO & $\begin{array}{l}\text { American Samoa, Brunei Darussalam, Cambodia, Cook Islands, Fed. States of } \\
\text { Micronesia, Fiji, French Polynesia, Kiribati, Lao PDR, Marshall Islands, Malaysia, } \\
\text { Niue, Papua New Guinea, Philippines, Samoa, Tonga, Tuvalu, Vanuatu, Vietnam, } \\
\text { Wallis and Futuna. }\end{array}$ & 45 & 24 \\
\hline SEARO & $\begin{array}{l}\text { Bangladesh, India, Indonesia, Maldives, Myanmar, Nepal, Sri Lanka, Thailand, } \\
\text { Timor-Leste. }\end{array}$ & 902 & 536 \\
\hline All Regions & 61 countries in total $^{d}$ & 1409 & 763 \\
\hline
\end{tabular}

AMRO Region of the Americas, AFRO African Region, EMRO Eastern Mediterranean Region, WPRO Western Pacific Region, SEARO South-East Asia Region

${ }^{a}$ Countries that started since 2007 are indicated in bold

${ }^{b}$ Data taken from $[5,6]$

${ }^{C} \mathrm{~A}$ conservative approach was taken and the number of uniquely treated individuals in any one country was assumed to be the maximum number of individuals treated in any single MDA for each country

${ }^{\mathrm{d}}$ Palau has passed the TAS survey but never started MDA so is not included 


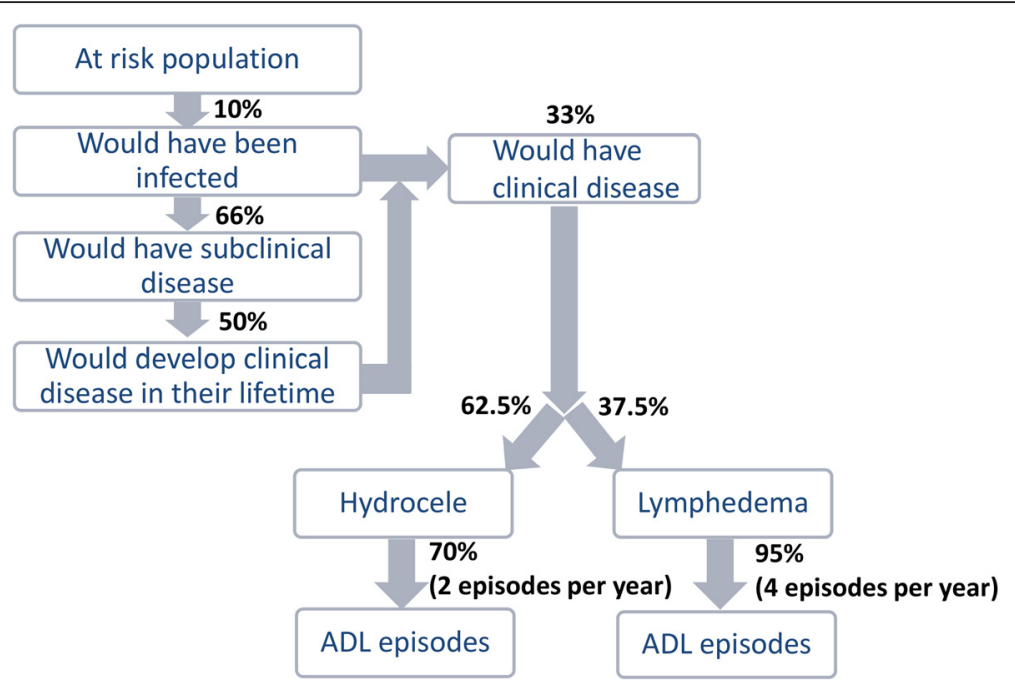

Fig. 2 Baseline model assumptions. Assumptions based on $[2,4]$. The sources for the parameters are outlined in Table 3

from the MDA treatment provided under the GPELF (Fig. 3):

\section{Benefit Cohort 1: individuals protected from acquiring infection}

Since the beginning of the programme in 2000 through the end of 2014, over 5.6 billion doses of anthelmintics have been administered to populations in 61 of the endemic countries (Table 4 and Fig. 1). This mass treatment will have had a major impact on the rate of transmission and consequently the number of people still at-risk of infection (and therefore the incidence of clinical infections) (Fig. 4).

Though programmatic evidence suggests that effective transmission of LF might cease soon after the initiation of MDA, entomologic studies suggest that the decline in vector infection is more gradual [18]. We therefore approximated the reductions in the number at-risk for each country using a previously developed model which defines reductions in risk of infection among cohorts of treated populations following each treatment round (Fig. 3)
[18]. As populations are treated, their risk of infection diminishes progressively after each MDA. The model was parametrised based on previous studies, which estimated a relationship describing an 'average' rate-of-decline of vector infection over five treatment rounds (pooling data from available studies [19-25]). This method uses the progressive decrease in vector infection rates as an indicator for decreased transmission, and, therefore, reduced population at risk of LF.

The model therefore accounts for a gradual decline in transmission, namely reductions of pre-control levels of $50,75,88,94$ and $95 \%$ for the treated population following each of the first five MDA rounds respectively [18]. For this analysis, the reductions for the fifth MDA round onwards was set to $95 \%$ and not the previous $100 \%$ to account for potential residual transmission. These values were varied in the sensitivity analysis. The reductions in transmission are applied only to those treated and not the at-risk population as a whole (Fig. 3) [18].

The number of clinical infections prevented in this benefit cohort was estimated by assuming that in the

Table 3 Baseline model parameters (based on $[2,4]$ )

\begin{tabular}{|c|c|c|c|}
\hline Parameter & Hydrocele average estimate & Lymphedema average estimate & Source \\
\hline \multicolumn{4}{|l|}{ Acute Disease } \\
\hline Percentage of clinical patients who experience ADL episodes per year & $70 \%$ & $95 \%$ & {$[8,10-17]$} \\
\hline Frequency of ADL episodes for clinical patients (in absence of MDA) & 2 per year & 4 per year & {$[8,10-17]$} \\
\hline Average duration of an $\mathrm{ADL}$ episode & 4 days & 4 days & {$[8,10-17]$} \\
\hline Reduction in the frequency of $\mathrm{ADL}$ episodes by MDA & $50 \%$ & $50 \%$ & {$[33,36,37]$} \\
\hline \multicolumn{4}{|l|}{ Chronic Disease } \\
\hline Percentage in different clinical disease states & $62.5 \%$ & $37.5 \%$ & [7] \\
\hline Percentage of chronic disease alleviated by MDA & $10 \%$ & $15 \%$ & {$[20,30-35]$} \\
\hline
\end{tabular}

Due to the lack of region-specific data, a standard rate or proportion was utilized for each GPELF country. ADL acute adenolymphangitis, MDA mass drug administration 


\section{1) Individuals protected from acquiring infection}

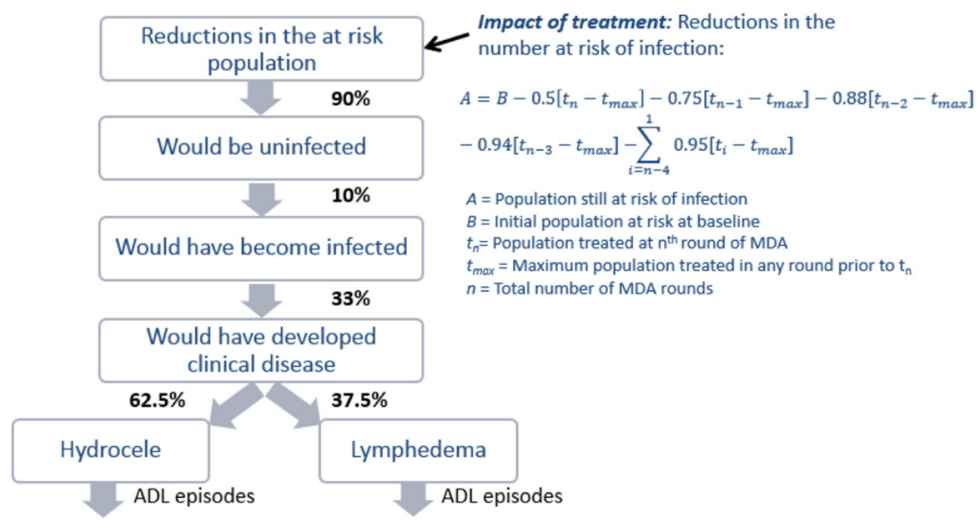

2) Individuals with existing subclinical morbidity protected from progression to clinical disease

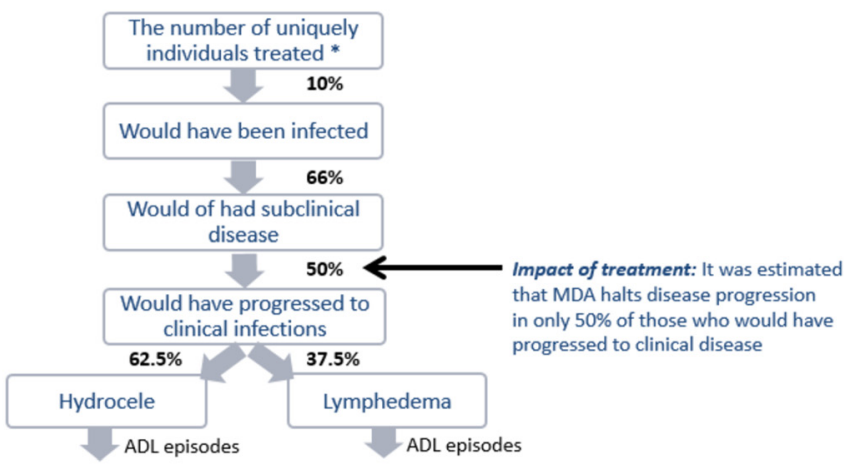

\section{3) Individuals with existing clinical morbidity for whom} clinical morbidity was alleviated

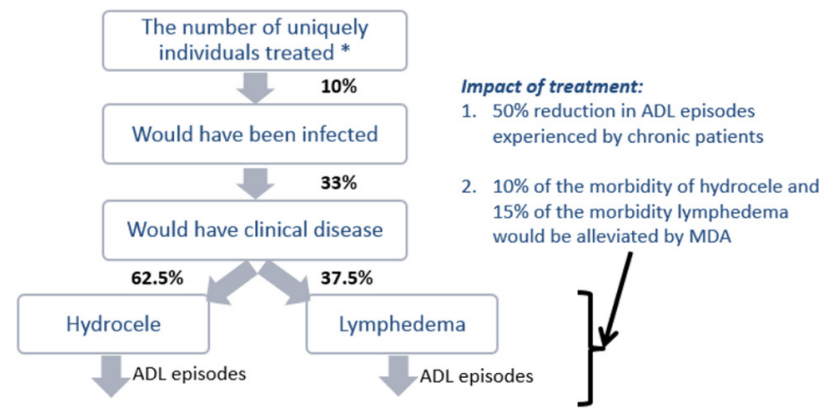

Fig. 3 Schematic representation of the benefit cohorts and the assumed impact of treatment. *The number of uniquely treated individuals in any one country was assumed to be the maximum number of individuals treated in any single MDA for each country

Table 4 Percentage of clinical patients seeking treatment

\begin{tabular}{llll}
\hline Parameter & Hydrocele average estimate & Lymphedema average estimate & Source \\
\hline Percentage of patients with ADL seeking treatment per episode & $55 \%$ (India: $70 \%)$ & $55 \%$ (India: 75 \%) & {$[8,11,14,44,46]$} \\
Percentage of chronic disease patients seeking treatment & $20 \%$ (India: $50 \%)$ & $30 \%$ (India: 55 \%) & {$[9,44,45]$}
\end{tabular}

Based on [4], though updated where appropriate. $A D L$ acute adenolymphangitis 


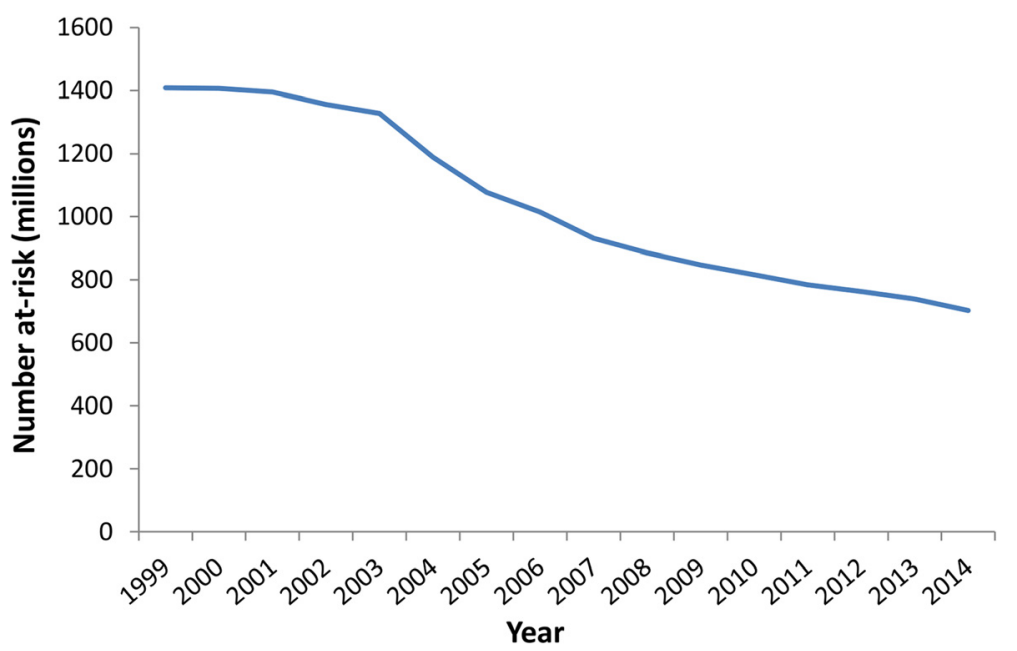

Fig. 4 The estimated decline in the number of people at-risk of LF infection over time. The reductions were projected using the model presented in [18] and Fig. 3. Since a few countries are still doing mapping/have not started, the numbers at-risk remain incompletely defined. If a country has passed the Transmission Assessment Survey (TAS) in all of its implementation units it was assumed to have an at-risk population of zero (from that point forward)

absence of MDA, approximately $10 \%$ of the projected population no longer at-risk would have become infected $[2,4]$, and $33 \%$ of those would have developed clinical disease (Fig. 3). This is a modification of the previous analysis [4], which modelled newborns who are protected from infection over their lifetimes and other individuals protected from acquiring infection separately. The updated model [18] was used as it more accurately quantifies the impact of MDA on transmission and the reduction of the at-risk population as a whole.

The 17 countries that have passed the Transmission Assessment Survey (TAS) for all of their endemic districts/implementation units and stopped MDA were assumed to have an at-risk population of zero from that point onwards (before passing the TAS they had the transmission reduction rates described previously (see Fig. 3)).

\section{Benefit Cohort 2: individuals with existing subclinical morbidity protected from progression to clinical disease}

Based on previous studies it was assumed that approximately $66 \%$ of individuals infected with LF have subclinical morbidity [1] and about $50 \%$ of these would progress to overt clinical disease in their lifetimes $[2,4]$. As in the previous analysis [2, 4], it was conservatively assumed that MDA halts disease progression in $50 \%$ of those who would have progressed from subclinical to clinical disease [26].

Though the number of individuals treated in each MDA round for each country is known [5], it is not possible to estimate how many different individuals received treatment across multiple MDA rounds. Consequently, a conservative approach was taken and the number of uniquely treated individuals in any one country was assumed to be equal to the maximum number of individuals treated in any single MDA round [5].

\section{Benefit Cohort 3: individuals with existing clinical morbidity for whom clinical morbidity was alleviated}

There remains considerable uncertainty regarding the extent to which MDA improves the state of morbidity in those already suffering from hydrocele or lymphedema. However, several studies have provided preliminary evidence that repeated rounds of MDA may alleviate some LF clinical morbidity [20, 27-31]. As in the previous analysis [4], a conservative estimate of $10 \%$ of the morbidity of hydrocele cases and $15 \%$ of the morbidity of lymphedema cases being alleviated by MDA was assumed. However, due to the uncertainties surrounding these values, they were varied in the sensitivity analysis (ranging from $0 \%$ alleviation up to $69-90 \%$ based on the lower and upper boundaries cited by the literature [20, 30-35]).

Treatment is also known to reduce the frequency of ADL episodes experienced by chronic patients [33, 36, 37]. Due to the uncertainty surrounding this parameter, we assumed a conservative estimate of a $50 \%$ reduction in the frequency of ADL episodes in chronic patients and varied this between 15 and $88 \%$ in the sensitivity analysis [33, 36, 37] (Fig. 3).

\section{Calculating the total health and economic benefits of the GPELF}

In this paper we investigated the total health and economic impact of the GPELF for the three benefit cohorts defined in the previous section for the years 2000-2014. In the absence of transmission, protection from LF infection 
and disease progression is lifelong, thus it is necessary to aggregate the total health and economic benefit gained over the remaining lifetime of each benefit cohort population (Fig. 5). Life expectancy estimates were taken from existing tables [38]. The calculations were performed for each country individually to account for country-specific differences (such as life expectancy, mortality rates, medical expenses, wages etc.). All calculated economic benefits were discounted at $3 \%$ to the base year of 2014 .

The perspective of the analysis was that of the society as a whole - including the costs incurred by the patients (both direct and indirect costs), and national health systems.

\section{Duration of health and economic benefits}

The duration of the health and economic benefits was dependent on A) the age of onset of clinical disease (assumed to be 20 years old [2] in each country), B) the average life expectancy (differing by country), and C) the mean age at which an individual received MDA treatment (differing by cohort). For the latter the following assumptions were made (based on [4]):

- Individuals protected from acquiring infection (Benefit Cohort 1): The model assumes that the average age at treatment (and thus protection) for this cohort is 20 years.

- Individuals with subclinical morbidity at the time of MDA (Benefit Cohort 2): Though subclinical infection is common in early childhood, the model assumes that the average age at treatment (and thus protection) for subclinical patients is also 20 years.

- Individuals with clinical disease at the time of MDA (Benefit Cohort 3): The model assumes these individuals to be 30 years old on average when they receive MDA. This estimate implies that clinical disease patients have been living with their condition for an average of 10 years, since onset of clinical disease is assumed to be 20 years of age.

In the model, these average ages (20,20 and 30 years) were used to encompass the entire age range of individuals within each benefit cohort population at the time of treatment - accounting for the fact that, in reality, some individuals receiving treatment will be younger or older than the average age (Fig. 5) [4].

\section{Population size}

This study projects the total health and economic impact of the first 15 years of the GPELF by aggregating the benefits over the lifetime of the 2000-2014 benefit cohorts. No projections are made for the expansion of MDA programmes after 2014 or their resulting benefits. The size of the benefit cohort populations were set to decrease dictated by the country-specific mortality rates [39]. Because the model population size decreases over time, the economic-benefit denominator was analysed in

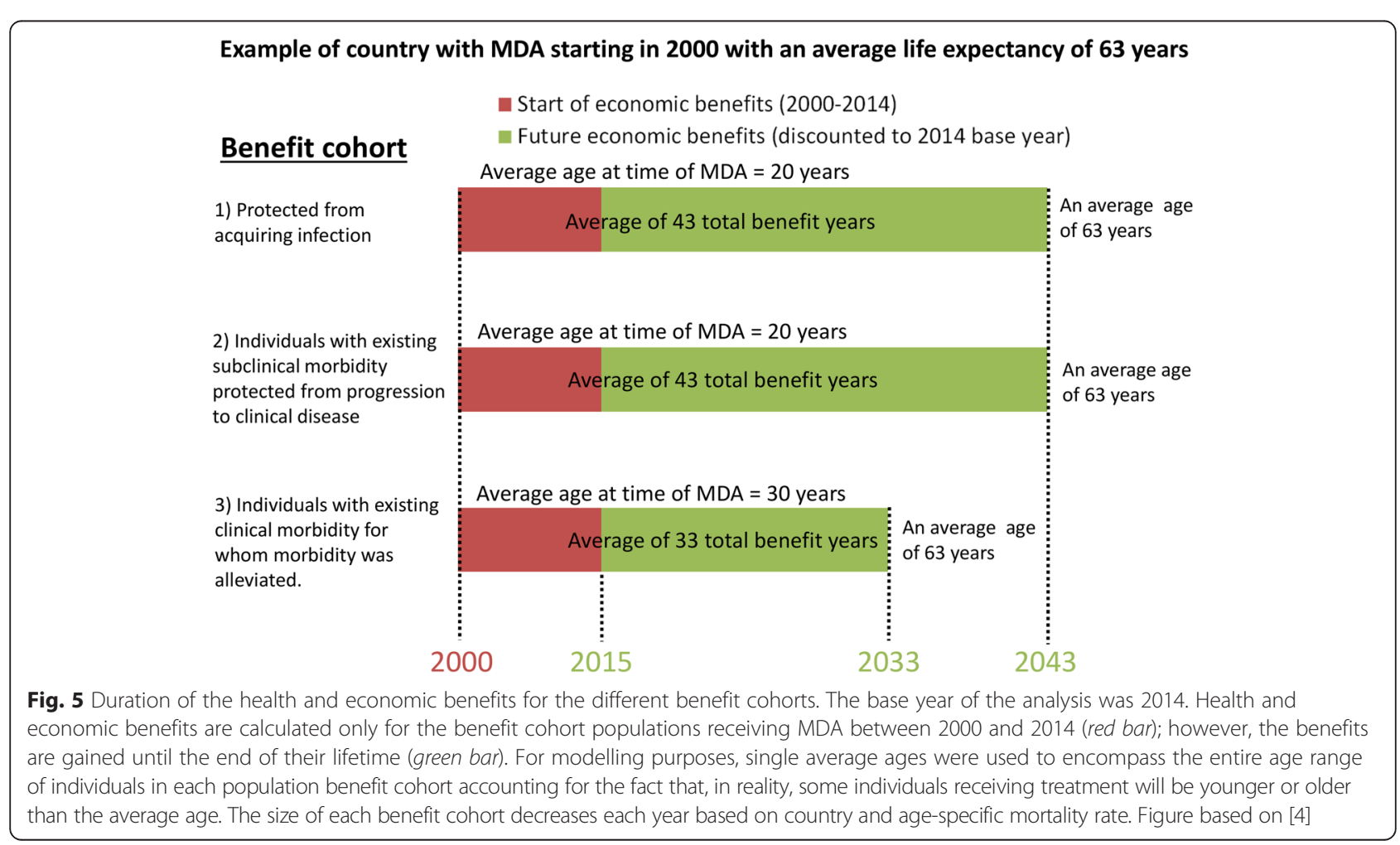


person-years (the sum of each year lived by each individual in each benefit cohort population).

\section{DALYs averted}

The number of disability-adjusted life years (DALYs) averted due to the GPELF (2000-2014) was estimated by applying the 2010 Global Burden of Disease (GBD) disability weight of $0.11(0.073-0.157)$ [40] to the number of clinical (symptomatic) LF person years averted (sum of each year lived by each individual in the benefit cohort population (Fig. 5)). No distinction in the disability weight was made between hydrocele and lymphedema. Based on the methodology employed by the 2010 GBD study we did not apply a discount rate or age weighting to the DALY estimates [41].

\section{Economic costs prevented}

All of the economic benefits from MDA were assumed to arise from individuals within the benefit cohorts (i.e. individuals who would have had clinical disease without the GPELF). The economic costs prevented are comprised of both:

- Direct costs: representing the costs associated with medical resource utilization, which include the cost borne by the patients (i.e. for the medicines and transport etc.) and the health system (i.e. for health care personnel and capital resources etc.) [42].

- Indirect costs: defined as the expenses incurred from the cessation or reduction of work as a result of the morbidity and mortality associated with a given disease [42].

\section{Direct costs}

Patient medical expenses Medical expenses are incurred by patients with clinical morbidity seeking treatment (Table 4). Patients were assumed either to go to a public or private health facility or to perform self-treatment/use traditional healers (Additional file 2: Table S1). Chronic disease sufferers who seek treatment following bouts of severe pain and swelling were assumed to receive antiinflammatory medicines (ibuprofen (400 mg), and paracetamol (500 mg)). Patients seeking treatment for ADL were assumed to receive the same anti-inflammatory medicines and antibiotics (amoxicillin $(500 \mathrm{mg})$ ) [43]. We conservatively assumed that the standard treatment course was 8 days.

Both the proportion of clinical patients who seek treatment (Table 4) and the treatment source (Additional file 2: Table S1) were dependent on the morbidity type. In India, a higher proportion was assumed to seek treatment and to go to health facilities (Table 4). Due to lack of data, a lower global estimate was used for the other
GPELF counties (Table 4). It was also assumed that the chronic hydrocele and lymphedema patients seeking treatment would do so an average two and three times per year respectively.

As in the previous analysis [4] it was assumed that for individuals seeking treatment at health facilities (both public and private), $50 \%$ of their total medical expenses was for the medicines, $30 \%$ for consultation fees and $20 \%$ for transport, food, and accommodation [11, 44-46]. Median international reference prices for a course of amoxicillin (500 mg), ibuprofen (400 mg), and paraceta$\mathrm{mol}(500 \mathrm{mg}$ ) were collected from the Management Sciences for Health International drug price indicator guide [47]. These were adjusted to obtain country-specific cost estimates for both public and private treatment using the Median Price Ratios from the relevant Health Action International database [48]. For countries not listed, the lowest value within the same region was used as a proxy. These medicine costs (which are $50 \%$ of the total cost) were doubled to arrive at the estimated total medical expenses. For self-treating individuals, only the private medicine costs for ibuprofen and paracetamol were attributed to the total medical expenses. A summary of the medical expenses for each region is shown in Additional file 2: Table S2.

Health system costs Reductions in the number of clinical cases will also reduce the amount of medical care that needs to be provided for LF, and consequently financial costs to the health systems of endemic countries. To estimate these patient-service savings, country-specific costs for a consultation at a rural primary health centre were gathered from the WHO CHOICE database [49]. These costs were then multiplied by the number of clinical LF cases averted, the percentage that seek treatment and go to a public health facility (Table 4 and Additional file 2: Table S1), and the average number of treatment visits per year (Table 3). Note that the WHO CHOICE database was updated in 2011, hence the health system costs are different from [4]. A summary of the average health system costs per visit for each region is shown in Additional file 2: Table S2.

Due to the absence of data regarding the cost and actual number of hydrocele surgeries performed in endemic countries, it was not possible to incorporate their costs into the analysis [43]. However, the proportion of total direct costs related to hydrocele surgeries would likely be small due to the still inadequate, relatively low frequency of hydrocelectomies.

\section{Indirect costs}

Lost wages Clinical LF is debilitating, and patients are unable to work the same number of hours as equivalent 
workers not experiencing clinical symptoms (although chronic disease is less debilitating than acute (ADL) episodes). Reduced work hours and economic activity due to LF morbidity results in income loss for clinically infected individuals (an indirect cost).

Our assumptions regarding the reduction in productivity due to LF morbidity (Table 5) were based on a number of studies reporting the average number of hours worked by those with clinical disease compared to LF disease free controls (therefore accounting for employment rates in the local study setting). The difference between cases and controls is the percentage of working hours lost due to LF morbidity. It should be noted that these cost-ofillness studies must be interpreted with a degree of caution, as they are often highly sensitive to methodological assumptions; hence we employed conservative values (Table 5) and varied them over a wide range in the sensitivity analysis. We included both the productivity lost due to chronic disease and ADL episodes within our calculations of the indirect costs (Table 5).

As in [4], the indirect cost estimates were calculated using the human capital approach (i.e. based on the income foregone as a result of illness (any hour not worked is counted as an hour lost)) [50-52]. It should be acknowledged that approximating the income for individuals with LF is difficult; for example many of those infected are subsistence farmers who do not participate in the formal labour market [4]. For this reason, a combination of four wage sources was used to estimate the country-specific fair market value of time for an agricultural worker with LF infection (as in [4]): A) The International Labour Organization's LABORSTA database (which lists country-specific average wages for agricultural field workers) [53]; B) The World Bank's World Development Indicators (which lists a country-specific average value added per agricultural worker) [54]; C) The International Labour Organization's
Minimum Wages Database [55] and D) United States Department of State Country Reports on Human Rights Practices (which both list country-specific minimum wages) [56]. To ensure a conservative estimate, the lowest wage value was used for countries listed by more than one of the sources. For countries not listed by any of the four sources, the lowest value within the same region was used as a proxy. It was assumed that all individuals at-risk of or infected with LF would have been potentially economically active otherwise, and would work 300 days per year (six days a week, 50 weeks a year), 8 hours a day. A summary of the wages for each region and source is shown in Table 6.

\section{Cost standardization}

To standardize the treatment prices and wages over different time periods, all estimates were adjusted for inflation using the gross domestic product price deflator and are expressed in US\$ 2014 prices [57]. Estimates were then converted from local currencies to US dollars using the average exchange rates for 2014 [58].

\section{Discounting}

The base year for calculating economic benefits was set to 2014. The economic benefits were discounted at $3 \%$ per year from this time point in accordance to guidelines set by WHO-CHOICE [59]. The discount rate was varied (0-6\%) within the sensitivity analysis [59]. No discount rate was applied for the years prior to the base year (2014). The DALYs averted/health benefits were not discounted in this analysis [41].

\section{Sensitivity analysis}

Sensitivity analysis was performed in the following areas; A) Disease progression and incidence rates, B) Patient medical expenses and treatment seeking behaviour, $\mathrm{C}$ )

Table 5 Economic model parameters

\begin{tabular}{|c|c|c|c|c|}
\hline Disease type & Parameter & $\begin{array}{l}\text { Hydrocele average } \\
\text { estimate }\end{array}$ & $\begin{array}{l}\text { Lymphedema average } \\
\text { estimate }\end{array}$ & Sources \\
\hline Acute & Average patient medical expenses per ADL episode & Country-specific (US\$1.18 $)$ & Country-specific (US\$1.18 $\left.{ }^{\mathrm{a}}\right)$ & {$[8,11,44-48]$} \\
\hline Chronic & $\begin{array}{l}\text { Average patient medical expenses for chronic } \\
\text { disease per year }\end{array}$ & $\begin{array}{l}\text { Country-specific } \\
\left(U S \$ 0.70^{\mathrm{ac}}\right)\end{array}$ & Country-specific (US\$1.05 ac $)$ & {$[8,11,44-48]$} \\
\hline Acute & $\begin{array}{l}\text { Percentage of work hours lost per day during an } \\
\text { ADL episode }\end{array}$ & $75 \%{ }^{b}$ & $75 \%{ }^{b}$ & {$[12,14,16,87]$} \\
\hline Chronic & Percentage of work hours lost due to chronic disease & $15 \%{ }^{b}$ & $19 \%$ & $\begin{array}{l}{[12,43,45,} \\
46]\end{array}$ \\
\hline $\begin{array}{l}\text { Acute \& } \\
\text { chronic }\end{array}$ & $\begin{array}{l}\text { Average wage per day (minimum of sources } \\
\text { (Table 6)) }\end{array}$ & Country-specific (US\$1.50ª) & Country-specific (US\$1.50ª) & {$[53-56]$} \\
\hline Chronic & Work days per year & $300^{b, d}$ & $300^{b, d}$ & \\
\hline
\end{tabular}

Based on [4], though updated where appropriate

a Weighted average over all GPELF countries (based on the benefit cohort population size in each country) (Additional file 2: Table S2 and Table 6)

${ }^{b}$ Global estimate indicates a standard rate or proportion was utilized for each GPELF country. This is primarily due to a lack of supporting country-specific data

${ }^{\mathrm{C} C h r o n i c ~ h y d r o c e l e ~ a n d ~ l y m p h e d e m a ~ p a t i e n t s ~ a r e ~ a s s u m e d ~ t o ~ s e e k ~ t r e a t m e n t ~ o n ~ a v e r a g e ~ t w o ~ a n d ~ t h r e e ~ t i m e s ~ a ~ y e a r ~ r e s p e c t i v e l y ~}$

${ }^{\mathrm{d}}$ Assume an average 6 day work week, 50 weeks of the year

Costs are expressed in US\$ 2014 prices

$A D L$ acute adenolymphangitis 
Table 6 Summary of the different wage sources

\begin{tabular}{|c|c|c|c|c|c|c|}
\hline $\begin{array}{l}\text { WHO } \\
\text { region }\end{array}$ & $\begin{array}{l}\text { ILO LABORSTA (farm } \\
\text { worker average wage) }\end{array}$ & $\begin{array}{l}\text { World Bank (average value } \\
\text { per agricultural worker) }\end{array}$ & $\begin{array}{l}\text { ILO (minimum } \\
\text { wage) }\end{array}$ & $\begin{array}{l}\text { US State Department } \\
\text { (minimum wage) }\end{array}$ & $\begin{array}{l}\text { Overall average - } \\
\text { maximum of sources }^{a}\end{array}$ & $\begin{array}{l}\text { Overall average - } \\
\text { minimum of sources }\end{array}$ \\
\hline AMRO & $\$ 6.90$ & $\$ 27.36$ & $\$ 5.27$ & $\$ 5.17$ & $\$ 27.36$ & $\$ 5.11$ \\
\hline AFRO & $\$ 1.92$ & $\$ 8.18$ & $\$ 2.06$ & $\$ 2.16$ & $\$ 9.05$ & $\$ 1.01$ \\
\hline EMRO & $\$ 4.84$ & $\$ 18.26$ & $\$ 3.19$ & $\$ 5.00$ & $\$ 18.26$ & $\$ 3.00$ \\
\hline WPRO & $\$ 5.36$ & $\$ 9.06$ & $\$ 6.81$ & $\$ 6.74$ & $\$ 10.70$ & $\$ 4.98$ \\
\hline SEARO & $\$ 1.80$ & $\$ 3.47$ & $\$ 1.77$ & $\$ 3.75$ & $\$ 4.04$ & $\$ 1.47$ \\
\hline Average & $\$ 2.02$ & $\$ 5.10$ & $\$ 2.10$ & $\$ 3.42$ & $\$ 5.84$ & $\$ 1.50$ \\
\hline
\end{tabular}

AMRO Region of the Americas, AFRO African Region, EMRO Eastern Mediterranean Region, WPRO Western Pacific Region, SEARO South-East Asia Region, ILO International labour organization

Results in this paper use the "Overall average - minimum of sources" estimates

Values shown are weighted averages (based on the benefit cohort population size in each country)

${ }^{a}$ The overall maximum and minimum averages were estimated from all sources for each country individually, and then averaged by region (which is why the values are smaller than the regional database averages)

Costs are expressed in US\$ 2014 prices

For countries not listed in the database, the lowest value within the same region was used as a proxy

Lost productivity and wages, D) The discount rate and E) Impact of treatment. The parameters and ranges investigated are shown in Table 7.

\section{Ethical approval}

This study does not require ethical approval.

\section{Results}

Between 2000 and 2014, the GPELF has delivered 5.6 billion treatments to over 763 million people at least once, in 61 of the 73 identified endemic countries.

Using the model presented in Fig. 3 and the corresponding treatment data, we projected that the total benefit cohort of the GPELF (2000-2014) would consist of 46 million individuals (Table 8) (i.e. these individuals would have had clinical disease without the GPELF interventions). Of these, 21 million (45\%) were in Benefit Cohort 1 (would have acquired LF and subsequently progressed to clinical disease but were protected from infection due to reductions in transmission by MDA). The remaining 25 million were individuals who were already infected at the time of MDA treatment but benefited from halted disease progression (Benefit Cohort 2: 12.5 million (27 \%)), or alleviated clinical disease (Benefit Cohort 3: 12.8 million (28 \%)) (Table 8).

\section{Health benefits}

Administering MDA to such a large population has produced substantial health benefits over the first 15 years of the GPELF. We estimate that the programme would prevent 1,592 million years lived with chronic disease (36 million chronic cases) and 4,689 million ADL episodes over the lifetimes of the benefit cohorts (Table 9). This translates into approximately 175 (116-250) million DALYs averted - range depending on the $95 \%$ uncertainty range of the disability weight (Table 9).
The total health impact was smallest for the Alleviated clinical disease cohort (Benefit Cohort 3) despite its comparable population size (Table 8). This is due to the fact that the majority of this cohort were only experiencing reductions in the frequency of ADL episodes and not fully alleviated chronic disease (Table 9) (due to the assumed effects of treatment on morbidity (Table 3 and Fig. 3)). Furthermore, as members of this cohort were assumed to be older at the time of MDA, they have fewer years of economic benefit (and consequently a lower number of person-years in the benefit cohort (Fig. 5 and Table 8)).

\section{Economic benefits}

We estimated that on average, each individual in the benefit cohort will potentially avoid losing US $\$ 2095$ over his/her lifetime (US\$50 per year) (Tables 10 and 11). This is equivalent to the income earned by working 33.3 days per year (Table 10). Though these sums and averages vary between different regions (Table 10 and Additional file 2: Table S4), much of the variation can be attributed to higher wages in non-AFRO/SEARO countries (Table 6) (where only $4 \%$ of the treatments during this 15-year period have been given (Fig. 1)). It is important to note that each year after 2014, the economic benefit is discounted by $3 \%$ per year.

In total, we estimated that due to the notable health impact of the GPELF, individuals in the benefit cohort would avoid losing US\$96.9 billion in costs over their lifetimes. This total amount results from summing the prevented patient medical expenses (US\$2.9 billion) and potential income loss (US\$94 billion) prevented for these individuals (Table 11). Reductions in the number of clinical LF cases will also reduce the patient-service costs for the public health system. We estimated that approximately US $\$ 3.5$ billion in health system costs will be saved over the lifetime of the benefit cohort populations. Consequently, 
Table 7 Summary of the sensitivity analysis

\begin{tabular}{|c|c|c|c|}
\hline Parameter & $\begin{array}{l}\text { Hydrocele average } \\
\text { estimate }\end{array}$ & $\begin{array}{l}\text { Lymphedema average } \\
\text { estimate }\end{array}$ & Sources \\
\hline \multicolumn{4}{|l|}{ Disease Progression \& Incidence Rates } \\
\hline Percentage of clinical patients who experience ADL episodes per year & $70 \%(45-90 \%)$ & $95 \%(90-95 \%)$ & {$[8,10-17]$} \\
\hline Frequency of ADL episodes for clinical patients (in absence of MDA) & $2(0-7)$ per year & $4(0-7)$ per year & {$[8,10-17]$} \\
\hline Average duration of an $\mathrm{ADL}$ episode & $4(1-9)$ days & $4(1-9)$ days & {$[8,10-17]$} \\
\hline Disability weight for symptomatic LF infection & $0.11(0.073-0.157)$ & $0.11(0.073-0.157)$ & [40] \\
\hline \multirow[t]{3}{*}{ Mean age of the benefit cohorts (years) } & Cohort 1: $20(30)$ & Cohort 1: 20 (30) & \\
\hline & Cohort 2: 20 (30) & Cohort 2: $20(30)$ & \\
\hline & Cohort 3: 30 (40) & Cohort 3: $30(40)$ & \\
\hline \multicolumn{4}{|l|}{ Patient Medical Expenses and Treatment Seeking Behavior } \\
\hline \multirow[t]{2}{*}{ Percentage of patients with ADL seeking treatment per episode } & $55 \%(55-70 \%)$ & $55 \%(55-70 \%)$ & {$[8,11,14,44,46]$} \\
\hline & India 70 \% (70-98 \%) & (India $75 \%$ (75-98 \%)) & \\
\hline \multirow[t]{2}{*}{ Percentage of chronic disease patients seeking treatment } & $20 \%(20-50 \%)$ & $30 \%(30-55 \%)$ & {$[9,44,45]$} \\
\hline & India: $50 \%$ (41-80 \%) & India $55 \%$ (48-100 \%) & \\
\hline Average patient medical expenses per ADL episode & $+-20 \%$ of baseline value & $+-20 \%$ of baseline value & {$[8,11,44-48]$} \\
\hline Average patient medical expenses for chronic disease per year & $+-20 \%$ of baseline value & $+-20 \%$ of baseline value & {$[8,11,44-48]$} \\
\hline \multicolumn{4}{|l|}{ Lost Productivity \& Wages } \\
\hline Work days per year & $300(261-365)$ days & $300(261-365)$ days & \\
\hline Percentage of work hours lost per day during an ADL episode & $75 \%(50-93 \%)$ & $75 \%(50-93 \%)$ & {$[12,14,16,87]$} \\
\hline Percentage of work hours lost due to chronic disease & $15 \%(9-24 \%)$ & $19 \%(11-31 \%)$ & {$[12,43,45,46]$} \\
\hline \multicolumn{4}{|l|}{ Discounting } \\
\hline Discount rate & $3 \%(0-6 \%)$ & $3 \%(0-6 \%)$ & [59] \\
\hline \multicolumn{4}{|l|}{ Impact of Treatment } \\
\hline \multirow[t]{5}{*}{ The reduction in transmission experienced by the treated population } & Year 1: 50 \% (35 \%) & Year 1: $50 \%$ (35 \%) & [18] \\
\hline & Year 2: $75 \%$ (53 \%) & Year 2: $75 \%$ (53 \%) & \\
\hline & Year 3: $88 \%$ (62 \%) & Year 3: $88 \%$ (62 \%) & \\
\hline & Year 4: $94 \%$ (66 \%) & Year 4: $94 \%$ (66 \%) & \\
\hline & Year $595 \%$ (67\%) & Year $595 \%$ (67\%) & \\
\hline Reduction in the frequency of $\mathrm{ADL}$ episodes by MDA & $50 \%(15-88 \%)$ & $50 \%(15-88 \%)$ & {$[33,36,37]$.} \\
\hline Percentage of chronic disease alleviated by MDA & $10 \%(0-90 \%)$ & $15 \%(0-69 \%)$ & {$[20,30-35]$} \\
\hline
\end{tabular}

Based on [4], though updated where appropriate. ADL acute adenolymphangitis, MDA mass drug administration

Table 8 Summary of the benefit cohorts

\begin{tabular}{lllll}
\hline Benefit cohort & $\begin{array}{l}\text { Population size } \\
\text { (millions) }\end{array}$ & $\begin{array}{l}\text { Average age at MDA } \\
\text { treatment }\end{array}$ & $\begin{array}{l}\text { Average years of health and } \\
\text { economic benefit }^{{ }^{a}}\end{array}$ & $\begin{array}{l}\text { Person-years } \\
\text { (millions) }^{\mathrm{b}}\end{array}$ \\
\hline 1. Protected from acquiring infection & 21 & 20 & 45.6 & 938 \\
2. Subclinical morbidity prevented from progressing & 12.5 & 20 & 45.6 & 551 \\
3. Alleviated clinical disease & 12.8 & 30 & 35.6 & $450^{c}$ \\
Total & 46 & - & - & 1,939 \\
\hline
\end{tabular}

${ }^{\mathrm{a} B a s e d}$ on a global weighted average life expectancy of 64.6 years (weighted based on the benefit cohort population size in each endemic country) ${ }^{\mathrm{b}}$ The sum of the number of years lived by each individual in the benefit cohort population. (Equal to the benefit cohort population multiplied by the average years of health and economic benefit (after adjusting for mortality))

IIncludes both those with alleviated chronic disease and these with reduced frequency of ADL episodes (Fig. 3) 
Table 9 Projected health impact of the GPELF (2000-2014) over lifetime of the benefit cohorts

\begin{tabular}{lllll}
\hline Benefit cohort & $\begin{array}{l}\text { Number of chronic cases } \\
\text { averted (millions) }\end{array}$ & $\begin{array}{l}\text { Years of chronic disease } \\
\text { averted (millions) }\end{array}$ & $\begin{array}{l}\text { Number of acute (ADL) } \\
\text { episodes averted (millions) }\end{array}$ & $\begin{array}{l}\text { DALYs averted } \\
\text { (millions) }^{\text {a }}\end{array}$ \\
\hline 1. Protected from acquiring infection & 21 & 938 & 2,157 & $103(68-147)$ \\
2. Subclinical morbidity prevented from progressing & 12 & 551 & 1,267 & $62(41-88)$ \\
3. Alleviated clinical disease & 3 & 104 & 1,264 & $11(8-16)$ \\
Total & 36 & 1,592 & 4,689 & $175(116-250)$ \\
\hline
\end{tabular}

${ }^{a}$ Range based on the $95 \%$ uncertainty interval of the disability weight (Table 7)

See Additional file 2: Table S3 for the results stratified by WHO region. $A D L$ acute adenolymphangitis

the total economic impact for both the individuals in the benefit cohort and the health system was estimated to be potentially US $\$ 100.5$ billion (Table 11 ).

\section{Economic benefits by cost type}

Approximately $93.6 \%$ of the projected total economic benefit can be attributed to the prevention of reduced productivity and subsequent income loss - an indirect cost (Fig. 6 and Table 11). The remaining benefit was related to prevented patient medical expenses $(2.9 \%)$ and health system costs prevented $(3.5 \%)$ - both direct costs. The relatively low proportion for prevented patient medical expenses was attributable to the low frequency of treatment seeking behaviour and relatively inexpensive medicine packages relative to the day-to-day accumulation of lost income from reduced economic activity.

\section{Economic benefits by morbidity type}

The total economic benefits accrued by populations protected from hydrocele were approximately equal to those from lymphedema (Fig. 7). This result occurred because the greater average disability of lymphedema patients (Table 3) offsets the estimated higher proportion of clinical disease patients with hydrocele $(62.5 \%$ vs $37.5 \%)$.

Prevented chronic disease accounted for about $81 \%$ of the total economic benefits (Fig. 7). This is to be expected, as though acute episodes are more debilitating, they have a short duration (8-16 days per year) - whereas the chronic condition is a life-long disability (Table 3 ).

\section{Sensitivity analysis}

To determine how sensitive the results were to variation in the input parameters and assumptions, the model projections were subjected to univariate sensitivity analysis (see Table 7 for a full description).

The projected impact on health was found to be very robust, with the number of DALYs averted only being reduced by $17 \%$ when assuming more conservative reductions in transmission, and $18 \%$ when increasing the mean age of the benefit cohorts by 10 years (Additional file 2: Table S5). When assuming that MDA has no impact regarding alleviating established chronic disease, the number of DALYs averted only decreased by $7 \%$ (and increased by $37 \%$ when using the upper range of reported values for this parameter) (Additional file 2: Table S5). The number of DALYs averted was sensitive to the assumed disability weight. However, even when using the lower bound (0.073) for the disability weight [40], we still projected that 116 million DALYs would be averted.

The sensitivity of the economic benefit of the GPELF to the different parameters is shown in the tornado diagram in Fig. 8 (which illustrates the percentage change in the total economic benefit when changing each of the model parameters in Table 7). The results were most sensitive to the assumed percentage of work hours lost due to chronic disease and when using the lower bound the total economic benefit decreased by 31 \% (Fig. 8). The Figure also illustrates that if a lower discount rate was assumed that the economic benefit would be even

Table 10 Costs prevented per individual of the benefit cohort population

\begin{tabular}{|c|c|c|c|c|}
\hline $\begin{array}{l}\text { WHO } \\
\text { region }\end{array}$ & $\begin{array}{l}\text { Annual medical expenses averted per } \\
\text { person within the benefit cohort }{ }^{\mathrm{a}}\end{array}$ & $\begin{array}{l}\text { Annual wage loss prevented per } \\
\text { person within the benefit cohort }\end{array}$ & $\begin{array}{l}\text { Annual economic benefit per } \\
\text { person within the benefit cohort }\end{array}$ & $\begin{array}{l}\text { Equivalent number of } \\
\text { days income per year }\end{array}$ \\
\hline AMRO & $\$ 1.75$ & $\$ 158.49$ & $\$ 160.24$ & 31 \\
\hline AFRO & $\$ 0.77$ & $\$ 30.15$ & $\$ 30.92$ & 31 \\
\hline EMRO & $\$ 0.62$ & $\$ 102.54$ & $\$ 103.17$ & 34 \\
\hline WPRO & $\$ 1.32$ & $\$ 160.07$ & $\$ 161.39$ & 32 \\
\hline SEARO & $\$ 1.91$ & $\$ 50.37$ & $\$ 52.27$ & 36 \\
\hline Average & $\$ 1.52$ & $\$ 48.48$ & $\$ 50.00$ & 33.3 \\
\hline
\end{tabular}

AMRO Region of the Americas, AFRO African Region, EMRO Eastern Mediterranean Region, WPRO Western Pacific Region, SEARO South-East Asia Region. Costs are expressed in US\$ 2014 prices

aDoes not include reduction in costs to the health system (Additional file 2: Table S4)

${ }^{\mathrm{b}}$ Annual economic benefit per person within the benefit cohort divided by the average wage estimate for that region (Table 6 ) 
Table 11 Total costs prevented for individuals and the health systems over lifetime of the benefit cohorts

\begin{tabular}{|c|c|c|c|c|c|}
\hline Benefit cohort & $\begin{array}{l}\text { Direct costs for } \\
\text { individuals prevented - } \\
\text { medical expenses (millions) }\end{array}$ & $\begin{array}{l}\text { Indirect costs for } \\
\text { individuals prevented - lost } \\
\text { wages (millions) }\end{array}$ & $\begin{array}{l}\text { Direct costs for the } \\
\text { health system } \\
\text { prevented (millions) }\end{array}$ & $\begin{array}{l}\text { Total costs } \\
\text { prevented } \\
\text { (billions) }\end{array}$ & $\begin{array}{l}\text { Lifetime benefit per } \\
\text { individual within the } \\
\text { benefit cohort }^{\mathrm{a}}\end{array}$ \\
\hline 1. Protected from acquiring infection & $\$ 1,376$ & $\$ 52,513$ & $\$ 1,813$ & $\$ 55.70$ & $\$ 2,569$ \\
\hline $\begin{array}{l}\text { 2. Subclinical morbidity prevented } \\
\text { from progressing }\end{array}$ & $\$ 818$ & $\$ 31,273$ & $\$ 1,063$ & $\$ 33.2$ & $\$ 2,572$ \\
\hline 3. Alleviated clinical disease & $\$ 744$ & $\$ 10,210$ & $\$ 664$ & $\$ 11.6$ & $\$ 855$ \\
\hline Total & $\$ 2,938$ & $\$ 93,996$ & $\$ 3,540$ & $\$ 100.5$ & $\$ 2,095^{\mathrm{b}}$ \\
\hline
\end{tabular}

${ }^{\mathrm{a}}$ Does not include the economic benefit to the health system

beighted average

See Additional file 2: Table S4 for the results stratified by WHO region. Costs are expressed in US\$2014 prices

larger (and vice versa). The sensitivity analysis stratified by cost type is shown in Additional file 2: Table S6.

\section{Discussion}

These results further highlight that LF is responsible for not only a severe physical burden but also a considerable economic burden (from both medical expenses and loss of income-generating activity). The notable and sustained losses in labour productivity for clinical LF patients make it even harder for those living in endemic areas to escape from poverty without the aid of MDA interventions.

We projected that due to the first 15 years of the GPELF 36 million chronic cases would be averted (Table 9). Over the lifetime of the benefit cohort, this corresponds to 175 (116-250) million DALYs being averted (Table 9).

We estimated that, as a result of the first 15 years of the GPELF, 46 million individuals will gain economic benefits due to prevented clinical disease (Table 8) and that members of this benefit cohort would avoid losing US\$96.9 billion in costs (an average of US\$2 095 per person) over their lifetime due to the GPELF (Table 11). For individuals within the benefit cohort this is equivalent to the income earned from working 33.3 days (or $11 \%$ of their average annual income (Table 10)). In addition to the economic benefits to individuals, we projected US $\$ 3.5$ billion in health system costs will be saved in endemic areas (Table 11). Such savings are critical for health systems in resource poor settings. Furthermore, it is important to acknowledge that the analysis did not account for the decreasing need for hydrocele surgeries due to the MDA, and is therefore underestimating the economic benefits to health systems. The total economic impact for both the individuals and the health systems was estimated to be US $\$ 100.5$ billion.

\section{Comparison to past estimates}

A previous analysis by $\mathrm{Chu}$ et al. [4] estimated that following the first 8 years of the GPELF (2000-2007), US $\$ 21.8$ billion of economic benefits will be gained in MDA-treated areas, in addition to US $\$ 2.2$ billion in health systems savings. The difference in values between the studies are primarily due to the following reasons.

1. The analysis presented in this paper estimated the impact of the GPELF between 2000 and 2014. Since 2007, the programme has expanded to an additional 13 countries and delivered over 3.68 billion more treatments (Table 2 and Fig. 1) - therefore the economic impact has increased.

2. The number of individuals protected from acquiring infection (Benefit Cohort 1) was estimated using a model [18] defining reductions in the risk of infection among cohorts of treated populations (Fig. 3). This is a modification of the previous analysis [4] - as the model [18] was not developed

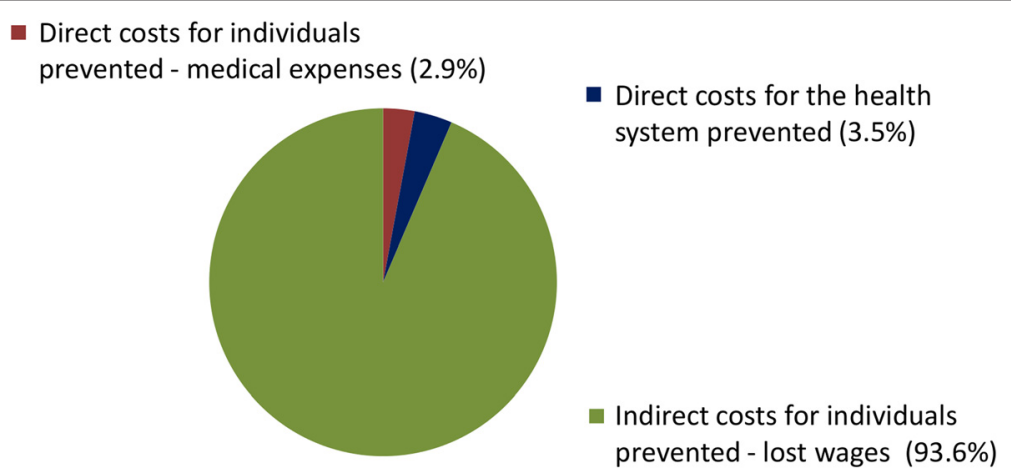

Fig. 6 Total economic benefit disaggregated cost type 


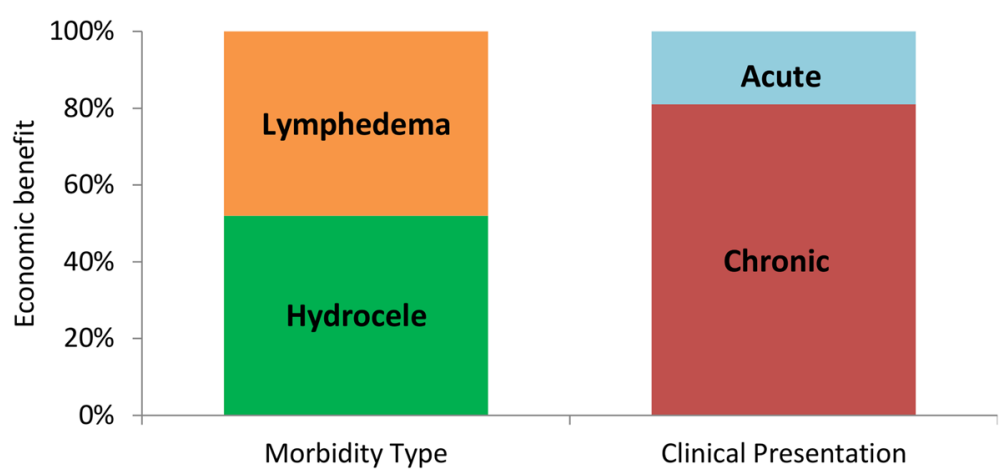

Fig. 7 Total Economic benefits by morbidity type, and clinical presentation

at that time. Consequently, the size of the benefit cohort is substantially larger in this more recent analysis.

3. The assumed wages were higher than the values used in [4] (due to inflation and the fact that the databases used to obtain wage estimates are now more complete).

4. WHO Choice updated its cost database in 2011 and consequently, the assumed health care costs (per visit) are different from those in Chu et al. [4].

Other studies corroborate the finding that the largest economic burden of LF results from indirect costs (see $[43,60])$. For example, it was estimated that in India, $8 \%$ of the potential male labour input was being lost due to hydrocele and lymphedema [45]. This was subsequently valued at US\$704 million per year [50]. In Ghana a similar values was reported, with more than $7 \%$ of potential labour lost [9].

That we know of, there are very few other analyses of health and economic benefits of global health programs as a whole. This makes it difficult to compare these estimates to those of other global disease control programmes. However, it should be noted that large health gains can also be expected for programmes targeting other NTDs as we move towards the goals set be the London Declaration and WHO 2020 NTD roadmap [61, 62].

Within [61] it was estimated that if the London Declaration goals were met between 2010 and 2030, 46.4 new clinical LF cases would be averted. This appears comparable with our estimate of 33 million new cases being averted over the lifetime of benefit cohorts 1 and

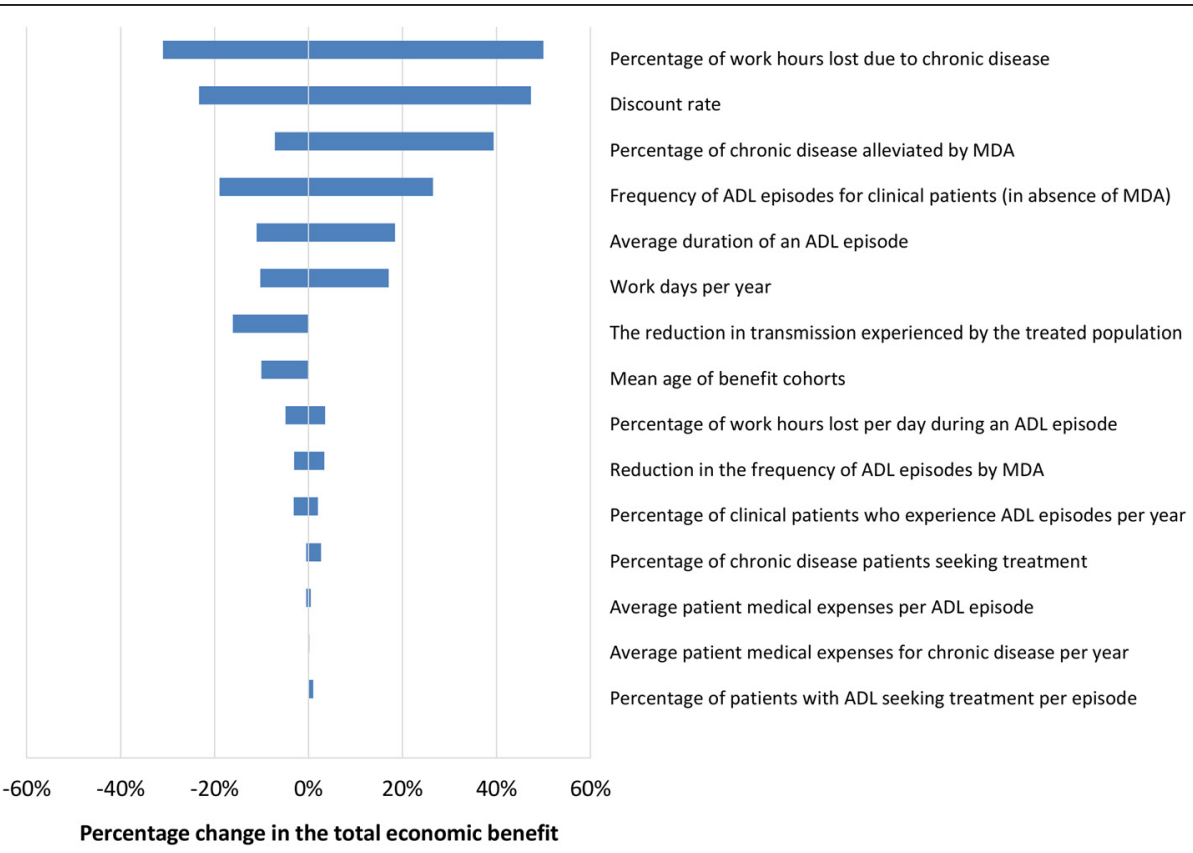

Fig. 8 Tornado plot illustrating the impact of the sensitivity analysis on the estimated total economic benefit of the GPELF (2000-2014). The parameter ranges investigated are shown in Table 7. Results stratified by cost type are shown in Additional file 2: Table S6 
2 (for the treatments given between 2000 and 2014) though it is difficult to directly compare the estimates as they are analysing different time horizons.

\section{Reduced productivity and lost wages}

The majority $(93.6 \%)$ of the economic benefit was projected to arise from potential income loss prevented (indirect costs). A variety of methods in valuing working time have been incorporated in economic analyses of similar tropical diseases, including the examination of minimum wages [63], average value added per agricultural worker [64], and proxies from prior studies in similar settings [65]. We used a combination of four wage sources to estimate a fair market value of time for an agricultural worker with LF infection (to ensure a conservative estimate, the lowest wage value was used for countries listed by more than one of the sources). For women, economic activity includes time spent on non-agricultural household chores (an opportunity cost). Our calculations used the human capital approach (which counts any hour not worked by a patient as an hour lost (Table 1)) [50-52].

However, approximating the value of the income loss is difficult for a variety of reasons $[4,52]$. Firstly, the majority of this population is comprised of subsistence farmers who do not participate in the formal labour market, making it harder to place a value on their time [4]. Furthermore, although chronic patients may develop coping strategies to adapt to their condition and regain a degree of economic activity, many do so at the expense of lower-earning jobs that require less physical activity $[9,66]$ - which is difficult to quantify. In addition, many with severe morbidity will be confined to the home and likely have to give up income-generating activity completely [4]. It is also important to consider that many patients may be employed in occupations with higher wages than subsistence farmers (such as. weaving, mining, fishing) [4] and will therefore suffer a higher opportunity cost than assumed in this analysis; average incomes are also generally higher in urban areas, where up to a third of the LF burden in India exists [50, 67]. More socioeconomic research is necessary to yield greater accuracy in the estimates of the opportunity cost of LF and indirect economic benefits of the GPELF [4].

It should be noted that there was a substantial degree of variation in the wage estimates between the different databases (Table 6) and employment rates may vary across the different countries. To be conservative we used the lowest wage estimate for each country (Table 6). Furthermore, our analysis calculates indirect costs based on the equivalent hours and resulting wages lost from economic activity. However, this ignores the fact that as well as working less, LF patients may be less productive while at work [4]. For example, Ramu et al. found that though the reported time difference (hours worked) between LF infected and uninfected weavers was 15$20 \%$, the productivity gap was higher at $27 \%$ [68]. Additional research on the actual productivity burden of LF, will be invaluable in developing more precise economic benefit estimates in the future [4]. The sensitivity of the results to the assumed percentage of work loss is shown in Fig. 8 and Additional file 2: Table S6.

\section{Additional benefits of the GPELF Quality-of-life benefits}

The primary health outcome of the analysis was the number of DALYs averted. However, it is important to note that the prevention of LF infection and clinical disease has led to additional quality of life benefits, which are not captured by the DALY disability weight for LF or the estimated lost wages. For example, the stigma associated with infection can prevent patients from playing a full role in society, often resulting in reduced marital prospects. This can result in adverse social and economic repercussions not only for the patient but also their family [69]. Furthermore, children may have to miss school in order to care for a family member with LF, and infected children will be more likely to miss school or drop out completely [70]. In addition, both those suffering from clinical disease and their caregivers are more likely to suffer from depression which is not currently quantified in the GBD estimates for LF which has been shown to underestimate LF disease burden [69]. It should also be noted that DALYs fail to acknowledge the implications of context on the burden of disease, such as those for the poor -which is particularly important for NTDs [71]. Consequently, the true value of the GPELF will likely be higher than what is presented in this analysis.

\section{Economic and health impacts on other co-endemic diseases} The GPELF uses highly effective, broad-spectrum antiparasitic drugs (albendazole and ivermectin). Consequently, the programme has important ancillary benefits on other parasitic diseases (described in more detail in [2]):

- Benefit for children and for women-of-child-bearingage with intestinal parasites: Albendazole and ivermectin are also used to control the soiltransmitted helminths (STH). Consequently, the GPELF is having a notable impact on these diseases (Table 12). It is important to note that LF programmes co-administrating albendazole and ivermectin will have a much higher impact on Trichuris [72] than STH control programmes using standalonetreatments [73, 74]. Furthermore, these communitywide programmes will have a higher impact on hookworm (for which the majority of worms are harboured by adults) $[73,75,76]$. 
Table 12 Potential impact on soil-transmitted helminths

\begin{tabular}{|c|c|c|}
\hline Individuals reached & Target & Benefits \\
\hline $\begin{array}{l}212 \text { million children } \\
\text {-minimal estimate- }\end{array}$ & $\begin{array}{l}\text { Soil-transmitted helminths (intestinal parasites: } \\
\text { hookworm, roundworm, whipworm) }\end{array}$ & $\begin{array}{l}\text { Weight/height gain, learning ability, cognitive testin } \\
\text { school attendance, fitness, activity [88-91] }\end{array}$ \\
\hline \multicolumn{3}{|l|}{ Assumptions and reasoning } \\
\hline \multicolumn{3}{|c|}{$\begin{array}{l}\text { A) } 1.1 \text { billion treatments of albendazole given to children (aged 2-15 years old in countries treated with DEC and albendazole; 5-15 years old in } \\
\text { countries using ivermectin and albendazole) in } 61 \text { countries during MDAs 2000-2014 [5, 6]. }\end{array}$} \\
\hline \multicolumn{3}{|c|}{$\begin{array}{l}\text { B) The maximum number of children treated in any single MDA was determined for each country. The sum of these numbers indicates the } \\
\text { minimum total number of children treated }(212 \text { million) }[5,6] \text {. }\end{array}$} \\
\hline ndividuals reached & Target & Benefits \\
\hline $\begin{array}{l}177 \text { million women of childbearing age, } \\
\text { not pregnant (minimal estimate) }\end{array}$ & $\begin{array}{l}\text { Soil-transmitted helminths (intestinal parasites: } \\
\text { hookworm, roundworm, whipworm) }\end{array}$ & $\begin{array}{l}\text { Decreased anaemia [92], maternal mortality, infant } \\
\text { mortality; increased infant birth-weight [93] }\end{array}$ \\
\hline \multicolumn{3}{|l|}{ Assumptions and reasoning } \\
\hline \multicolumn{3}{|c|}{$\begin{array}{l}\text { A) } 947 \text { million treatments of albendazole given to non-pregnant women-of-childbearing-age (aged 15-49 years old) in } 61 \text { countries during } \\
\text { MDAs 2000-2014 [5, 6, 38]. }\end{array}$} \\
\hline \multicolumn{3}{|c|}{$\begin{array}{l}\text { B) The maximum number of such women treated in any single MDA was determined for each country }[5,6] \text {. The sum of these numbers indicates } \\
\text { the minimum total number of women-of-childbearing-age treated (177 million). } \\
\text { C) Since pregnancy is an exclusion criterion for LF treatment, the annual estimates thus derived were discounted by subtracting the estimated } \\
\text { percent of the female population that is pregnant at any given time. }\end{array}$} \\
\hline
\end{tabular}

Because individual country estimates of the prevalence and distribution of soil-transmitted helminths are generally not available, it was not possible to estimate directly the number of soil-transmitted helminths infections. However, a sizeable proportion of the albendazole and ivermectin treatments delivered for LF will have had a beneficial impact for children and women of childbearing age who harbour soil-transmitted helminths. The assumptions are outlined in [2]

- Benefit for people with scabies. Ivermectin is effective treatment for scabies and can cause the community prevalence to fall dramatically after a few rounds of treatment [77]. Cured individuals show improvements in sleep patterns and overall wellbeing and decreased incidence of skin infections and renal disease [78].

- Benefit for co-endemic onchocerciasis areas. Because of its broad geographic range, the GPELF has brought ivermectin treatment to millions of people living in onchocerciasis-endemic areas not previously targeted by onchocerciasis control programs (as these programmes generally focused only on communities where the prevalence of onchocerciasis exceeds $40 \%$ ) [79]. The GPELF is therefore likely contributing significantly to the elimination of onchocerciasis transmission.

\section{Limitations}

\section{Model assumptions and parameters}

Though the number of individuals treated in each MDA round for each country is known [5], it is not possible to estimate how many unique individuals received treatment across multiple MDA rounds. Consequently, a conservative approach was taken and the number of uniquely treated individuals in any one country was assumed to be the maximum number of individuals treated in any single MDA for each country - which in most cases will be an underestimate.

The two different drug regimens used in the GPELF were assumed to be equally effective in their effects both on LF disease and on the filarial infections themselves [80].
For simplicity, a single average age was used to encompass the entire age range of individuals within each benefit cohort population at the time of treatment (with the recognition that some of those receiving treatment will be younger or older than the average age). However, realistically the average age would vary in different countries. Though this assumption will affect the economic benefit in any given year it is unlikely to affect the total benefit across the benefit cohort population's lifetime (in the sensitivity analysis we found that if the mean ages were increased by 10 years, it would only decrease the total economic benefit by $10 \%)$. It should be noted that some of the clinical cases would be averted further into the future then our model is projecting. Consequently, some of the economic benefits may be under-discounted.

The limited amount of country-specific primary data available somewhat limits the breadth of analysis presented in this paper though, much of the literature originates from India and sub-Saharan African countries where the majority of the benefit cohort population resides. Furthermore, due to a lack of regional data, many of LF disease-specific parameters (e.g. ADL frequency and duration, work hours lost) were attributed a global standardized estimate. However, the sensitivity analysis included a range of different values and the overall results appear robust.

Due to the way that the DALYs are calculated (with the same disability weight applied to any symptomatic infection), individuals in Benefit Cohort 3 (Fig. 3) with reduced ADL frequency but persistent chronic disease still had the same DALY weight applied to them. Furthermore, 
due to the absence of data no excess mortality of clinical patients was assumed. These assumptions may lead to an underestimation of the health impact of the GPELF (in terms of the number of DALYs averted).

\section{Calculating the reductions in the at-risk population}

The model [18] used to estimate the reductions in the at-risk population is dependent on data from WHO PCT Databank [5] regarding the numbers of people treated each year for LF. However, this data is self-reported by national programs, and while in many cases it has been found to be similar to independent coverage surveys, there are areas where frequent over-reporting has been identified (discussed further in [80]). Such over-reported coverage would lead the model to overestimate the number of infections averted by the GPELF. In addition, though data from all three mosquito genera transmitting LF were used to generate the model parameters, the biological differences of the vectors (or vector density) are not currently differentiated [18]. Furthermore, the model does not take into account the possibility of re-infection or resurgence of suppressed infections in areas that miss rounds of treatment or in areas where the coverage has decreased from the previous year [18]. On the other hand, such resurgence is uncommon [1], and many features of the model may be underestimating the effects of the GPELF on decreasing the number of at-risk individuals. For example, within the model, the reductions in transmission are applied only to those that have been treated. Consequently, it does not capture the indirect or herd effects of MDA to the populations covered as a whole [18]. The model is also based on the maximum number treated each round (which will underestimate the number uniquely treated). Furthermore, the model does not 'zero out' an at-risk population in the country until all of its implementation units have programmatically passed the TAS [18].

Though the model has important limitations, ultimately we are projecting that after the distribution of 5.6 billion treatments, the global number at-risk for LF infection has halved -which intuitively seems conservative (Fig. 4). The model was parameterized based on data derived from a broad range of entomological studies undertaken during active LF MDA programs in different geographical settings, providing a reliable estimate of changes in transmission potential under MDA pressure. A dynamic transmission model (such as [81-83]) would be more ideal and accurate for quantifying the impact of MDA on transmission (and would account for the indirect or herd effects of the GPELF) [84]. However, in order to be accurate this would likely require more detailed coverage data (at least at the implementation unit level), as opposed to the reported national coverage data available.

\section{Conclusion}

Despite the limitations of any such analysis, this study indicates that substantial health and economic benefits have resulted from the first 15 years of the GPELF. We projected that due to the first 15 years of the GPELF 36 million chronic cases and 175 (116-250) million DALYs would be averted over the lifetime of the benefit cohort. It was estimated that due to this notable health impact, US $\$ 100.5$ billion will potentially be saved over the lifetimes of those that would have had clinical disease without the GPELF. This total amount results from summing the patient medical expenses (US\$3 billion), potential income loss (US\$94 billion), and costs to the health system (US\$3.5 billion) that were projected to be prevented over the lifetime of the benefit cohort. The results were subjected to sensitivity analysis and were most sensitive to the assumed percentage of work hours lost due to chronic disease (changing the total economic benefit between US\$69.30-150.7 billion). In addition, the GPELF would have both further quality-of-life benefits and benefits on other co-endemic diseases (such as STH) as well making the total health and economic value even greater than that presented here.

It is important to note that this large health and economic impact would be diminished if the control programmes were not continued until elimination is achieved and the infection was allowed to resurge.

Though this analysis made a number of assumptions, we attempted to be conservative in our approach. These results further highlight the value and importance of continued investment in the GPELF as additional resources will be necessary to assist the remaining countries in implementing programs for LF elimination $[4,85]$.

\section{Additional files}

Additional file 1: Multilingual abstract in the five official working languages of the United Nations. (PDF $323 \mathrm{~kb}$ )

Additional file 2: Table S1. The breakdown of where individuals receive treatment. Table $\mathbf{S} \mathbf{2}$. Regional specific patient medical expenses and health system costs. Table S3. DALYs averted stratified by WHO region. Table S4. Economic benefits for individuals and the health systems stratified by the WHO regions. Table S5. Impact of the sensitivity analysis on the projected health benefits of the GPELF (2000-2014). Table S6. Impact of the sensitivity analysis on the projected economic benefits of the GPELF (2000-2014). (DOCX $28 \mathrm{~kb}$ )

\section{Funding}

$\mathrm{HCT}$ and $\mathrm{AAB}$, are supported by London Centre for Neglected Tropical Disease Research (funded by GSK). MHB (employed by GSK) had a role in study design, and preparation of the manuscript.

\section{Authors' contributions}

Conceived and designed the original modelling framework: BKC, DAM, PJH, EAO and MHB. Coded the updated model and analysed the data: HCT and $A A B$. Wrote the first draft: $H C T$ and $A A B$. All authors read and approved the final version of the manuscript. 


\section{Competing interests}

MHB currently works for GlaxoSmithKline.

\begin{abstract}
Author details
'London Centre for Neglected Tropical Disease Research, London, UK. ${ }^{2}$ Department of Infectious Disease Epidemiology, School of Public Health, Faculty of Medicine, St Marys Campus, Imperial College London, Norfolk Place, London W2 1PG, UK. ${ }^{3}$ Neglected Tropical Diseases Support Center, Task Force for Global Health, Decatur, GA, USA. ${ }^{4}$ Rollins School of Public Health, Emory University, Atlanta, GA, USA. ${ }^{5}$ Global Health Programs, GlaxoSmithKline, London, UK.
\end{abstract}

Received: 5 February 2016 Accepted: 18 May 2016 Published online: 07 July 2016

\section{References}

1. Ottesen EA. Lymphatic filariasis: treatment, control and elimination. Adv Parasitol. 2006:61:395-441.

2. Ottesen EA, Hooper PJ, Bradley M, Biswas G. The global programme to eliminate lymphatic filariasis: health impact after 8 years. PLoS Negl Trop Dis. 2008;2(10):e317.

3. Remme JHF, Feenstra P, Lever PR, Medici AC, Morel CM. Tropical diseases targeted for elimination: chagas disease, lymphatic dilariasis, onchocerciasis, and leprosy. In: Jamison DT, Breman JG, Measham AR, editors. Disease control priorities in developing countries. New York: Oxford University Press; 2006. p. 433-49.

4. Chu BK, Hooper PJ, Bradley MH, McFarland DA, Ottesen EA. The economic benefits resulting from the first 8 years of the Global Programme to Eliminate Lymphatic Filariasis (2000-2007). PLoS Negl Trop Dis. 2010;4(6):e708.

5. World Health Organization. PCT databank: Lymphatic filariasis [http://www. who.int/neglected_diseases/preventive_chemotherapy/lf/en/].

6. World Health Organization. 489 Global programme to eliminate lymphatic filariasis: progress report, 2014. Wkly Epidemiol Rec. 2015;90(38):489-504.

7. Michael E, Bundy DA, Grenfell BT. Re-assessing the global prevalence and distribution of lymphatic filariasis. Parasitology. 1996;112(Pt 4):409-28.

8. Ramaiah KD, Ramu K, Kumar KN, Guyatt H. Epidemiology of acute filarial episodes caused by Wuchereria bancrofti infection in two rural villages in Tamil, Nadu, south India. Trans R Soc Trop Med Hyg. 1996;90(6):639-43.

9. Gyapong JO, Gyapong M, Evans DB, Aikins MK, Adjei S. The economic burden of lymphatic filariasis in northern Ghana. Ann Trop Med Parasitol. 1996;90(1):39-48.

10. Pani SP, Yuvaraj J, Vanamail P, Dhanda V, Michael E, Grenfell BT, Bundy DA. Episodic adenolymphangitis and lymphoedema in patients with bancroftian filariasis. Trans R Soc Trop Med Hyg. 1995;89(1):72-4.

11. Krishnamoorthy K. Estimated costs of acute adenolymphangitis to patients with chronic manifestations of bancroftian filariasis in India. Indian J Public Health. 1999;43(2):58-63.

12. Ramaiah KD, Radhamani MP, John KR, Evans DB, Guyatt H, Joseph A, Datta M Vanamail P. The impact of lymphatic filariasis on labour inputs in southern India: results of a multi-site study. Ann Trop Med Parasitol. 2000;94(4):353-64.

13. Babu BV, Nayak AN, Dhal K. Epidemiology of episodic adenolymphangitis: a longitudinal prospective surveillance among a rural community endemic for bancroftian filariasis in coastal Orissa, India. BMC Public Health. 2005;5:50.

14. Gyapong JO, Gyapong M, Adjei S. The epidemiology of acute adenolymphangitis due to lymphatic filariasis in northern Ghana. Am J Trop Med Hyg. 1996:54(6):591-5.

15. Kessel JF. Disabling effects and control of filariasis. Am J Trop Med Hyg. 1957;6(3):402-14. discussion, 415.

16. Gasarasi DB, Premji ZG, Mujinja PG, Mpembeni R. Acute adenolymphangitis due to bancroftian filariasis in Rufiji district, south east Tanzania. Acta Trop. 2000;75(1):19-28.

17. Sabesan S, Krishnamoorthy K, Pani SP, Panicker KN. Mandays lost dueto repeated attacks of lymphatic filariasis. Trends in Life Sciences. 1992;7:5-7.

18. Hooper PJ, Chu BK, Mikhailov A, Ottesen EA, Bradley M. Assessing progress in reducing the at-risk population after 13 years of the global programme to eliminate lymphatic filariasis. PLoS Negl Trop Dis. 2014;8(11):e3333.

19. Ramzy RM, El Setouhy M, Helmy H, Ahmed ES, Abd Elaziz KM, Farid HA, Shannon WD, Weil GJ. Effect of yearly mass drug administration with diethylcarbamazine and albendazole on bancroftian filariasis in Egypt: a comprehensive assessment. Lancet. 2006;367(9515):992-9.
20. Bockarie MJ, Tisch DJ, Kastens W, Alexander ND, Dimber Z, Bockarie F, Ibam E, Alpers MP, Kazura JW. Mass treatment to eliminate filariasis in Papua New Guinea. N Engl J Med. 2002;347(23):1841-8.

21. Bockarie MJ, Ibam E, Alexander ND, Hyun P, Dimber Z, Bockarie F, Alpers MP, Kazura JW. Towards eliminating lymphatic filariasis in Papua New Guinea: impact of annual single-dose mass treatment on transmission of Wuchereria bancrofti in East Sepik Province. P N G Med J. 2000;43(3-4):172-82.

22. Das PK, Ramaiah KD, Vanamail P, Pani SP, Yuvaraj J, Balarajan K, Bundy DA. Placebo-controlled community trial of four cycles of single-dose diethylcarbamazine or ivermectin against Wuchereria bancrofti infection and transmission in India. Trans R Soc Trop Med Hyg. 2001;95(3):336-41.

23. Kimura E, Spears GF, Singh Kl, Samarawickrema WA, Penaia L, Sone PF, Pelenatu S, Faaiuaso ST, Self LS, Dazo BC. Long-term efficacy of single-dose mass treatment with diethylcarbamazine citrate against diurnally subperiodic Wuchereria bancrofti: eight years' experience in Samoa. Bull World Health Organ. 1992;70(6):769-76.

24. Richards Jr FO, Pam DD, Kal A, Gerlong GY, Onyeka J, Sambo Y, Danboyi J, Ibrahim B, Terranella A, Kumbak D, et al. Significant decrease in the prevalence of Wuchereria bancrofti infection in anopheline mosquitoes following the addition of albendazole to annual, ivermectin-based, mass treatments in Nigeria. Ann Trop Med Parasitol. 2005;99(2):155-64.

25. Grady CA, de Rochars MB, Direny AN, Orelus JN, Wendt J, Radday J, Mathieu E, Roberts JM, Streit TG, Addiss DG, et al. Endpoints for lymphatic filariasis programs. Emerg Infect Dis. 2007;13(4):608-10.

26. Shenoy RK, Suma TK, Kumaraswami V, Rahmah N, Dhananjayan G, Padma S. Antifilarial drugs, in the doses employed in mass drug administrations by the Global Programme to Eliminate Lymphatic Filariasis, reverse lymphatic pathology in children with Brugia malayi infection. Ann Trop Med Parasitol. 2009;103(3):235-47.

27. Partono F, Maizels RM. Purnomo: towards a filariasis-free community: evaluation of filariasis control over an eleven year period in Flores, Indonesia. Trans R Soc Trop Med Hyg. 1989;83(6):821-6.

28. Casley-Smith JR, Jamal S, Casley-Smith J. Reduction of filaritic lymphoedema and elephantiasis by 5,6 benzo-alpha-pyrone (coumarin), and the effects of diethylcarbamazine (DEC). Ann Trop Med Parasitol. 1993;87(3):247-58.

29. Tisch DJ, Alexander ND, Kiniboro B, Dagoro H, Siba PM, Bockarie MJ, Alpers MP, Kazura JW. Reduction in acute filariasis morbidity during a mass drug administration trial to eliminate lymphatic filariasis in Papua New Guinea. PLoS Negl Trop Dis. 2011;5(7):e1241.

30. Partono F, Purnomo, Oemijati S, Soewarta A. The long term effects of repeated diethylcarbamazine administration with special reference to microfilaraemia and elephantiasis. Acta Trop. 1981;38(3):217-25.

31. Partono F. Treatment of elephantiasis in a community with timorian filariasis. Trans R Soc Trop Med Hyg. 1985;79(1):44-6.

32. Meyrowitsch DW, Simonsen PE, Makunde WH. Mass diethylcarbamazine chemotherapy for control of bancroftian filariasis through community participation: comparative efficacy of a low monthly dose and medicated salt. Trans R Soc Trop Med Hyg. 1996;90(1):74-9.

33. Ciferri F, Siliga N, Long G, Kessel JF. A filariasis-control program in American Samoa. Am J Trop Med Hyg. 1969;18(3):369-78.

34. Mackenzie CD, Lazarus WM, Mwakitalu ME, Mwingira U, Malecela MN Lymphatic filariasis: patients and the global elimination programme. Ann Trop Med Parasitol. 2009;103 Suppl 1:\$41-51.

35. March HN, Laigret J, Kessel JF, Bambridge B. Reduction in the prevalence of clinical filariasis in Tahiti following adoption of a control program. Am J Trop Med Hyg. 1960;9:180-4.

36. Fan PC, Peng HW, Chen CC. Follow-up investigations on clinical manifestations after filariasis eradication by diethylcarbamazine medicated common salt on Kinmen (Quemoy) Islands, Republic of China. J Trop Med Hyg. 1995;98(6):461-4

37. Das L, Subramanyam Reddy G, Pani S. Some observations on the effect of Daflon (micronized purified flavonoid fraction of Rutaceae aurantiae) in bancroftian filarial lymphoedema. Filaria J. 2003;2(1):5.

38. Health Nutrition and Population Statistics. [http://datatopics.worldbank.org/hnp/].

39. Global Health Observatory data repository. [http://apps.who.int/gho/data/ view.main.60280?lang=en]

40. Salomon JA, Vos T, Hogan DR, Gagnon M, Naghavi M, Mokdad A, Begum N, Shah R, Karyana M, Kosen S, et al. Common values in assessing health outcomes from disease and injury: disability weights measurement study for the Global Burden of Disease Study 2010. Lancet. 2012;380(9859):2129-43.

41. Murray CJL, Vos T, Lozano R, Naghavi M, Flaxman AD, Michaud C, Ezzati M, Shibuya K, Salomon JA, Abdalla S, et al. Disability-adjusted life years (DALYS) 
for 291 diseases and injuries in 21 regions, 1990-2010: a systematic analysis for the Global Burden of Disease Study 2010. Lancet. 2012;380(9859):2197-223.

42. Boccuzzi S: Indirect Health Care Costs. In: Cardiovascular Health Care Economics. Edited by Weintraub W. Totowa, NJ: Humana Press; 2003: 63-79.

43. Addiss DG, Brady MA. Morbidity management in the Global Programme to Eliminate Lymphatic Filariasis: a review of the scientific literature. Filaria J. 2007;6:2

44. Nanda B, Krishnamoorthy K. Treatment seeking behaviour and costs due to acute and chronic forms of lymphatic filariasis in urban areas in south India. Trop Med Int Health. 2003;8(1):56-9.

45. Ramaiah KD, Guyatt H, Ramu K, Vanamail P, Pani SP, Das PK. Treatment costs and loss of work time to individuals with chronic lymphatic filariasis in rural communities in south India. Trop Med Int Health. 1999;4(1):19-25.

46. Babu BV, Nayak AN, Dhal K, Acharya AS, Jangid PK, Mallick G. The economic loss due to treatment costs and work loss to individuals with chronic lymphatic filariasis in rural communities of Orissa, India. Acta Trop. 2002:82(1):31-8.

47. Management Sciences for Health. International Drug price Indicator Guide. [http://erc.msh.org/mainpage.cfm?file=1.0.htm\&module=DMP\&language=English].

48. Health Action International. Database of medicine prices, availability, affordability and price components. [http://www.haiweb.org/MedPriceDatabase/].

49. Cost effectiveness and strategic planning (WHO-CHOICE). Health service delivery costs. [http://www.who.int/choice/cost-effectiveness/inputs/health_service/en/].

50. Ramaiah KD, Das PK, Michael E, Guyatt H. The economic burden of lymphatic filariasis in India. Parasitol Today. 2000;16(6):251-3.

51. Wesisbrod BA. The valuation of human capital. J Polit Econ. 1961;69:425-36.

52. Lensberg BR, Drummond MF, Danchenko N, Despiégel N, François C. Challenges in measuring and valuing productivity costs, and their relevance in mood disorders. Clinicoecon Outcomes Res. 2013;5:565-73.

53. International Labour Organization's LABORSTA database, http://laborsta.lo.org/].

54. World Development Indicators. [http://data.worldbank.org/data-catalog/ world-development-indicators].

55. International Labour Organization's Minimum Wages Database. [http://www. ilo.org/ilostat]

56. United States Department of State Country Reports on Human Rights Practices. [http://www.state.gov/j/drl/rls/hrrpt/].

57. International Monetary Fund. [https://www.imf.org/external/pubs/ft/weo/ 2015/01/weodata/weoselgr.aspx].

58. Historical Exchange Rates. [http://www.oanda.com/currency/historical-rates/].

59. World Health Organization. Making choices in health: WHO guide to costeffectiveness analysis. Geneva: World Health Organization; 2003.

60. Keating J, Yukich JO, Mollenkopf S, Tediosi F. Lymphatic filariasis and onchocerciasis prevention, treatment, and control costs across diverse settings: a systematic review. Acta Trop. 2014;135:86-95.

61. de Vlas SJ, Stolk WA, le Rutte EA, Hontelez JAC, Bakker R, Blok DJ, Cai R, Houweling TAJ, Kulik MC, Lenk EJ, et al. Concerted efforts to control or eliminate neglected tropical diseases: how much health will be gained? PLoS Negl Trop Dis. 2016;10(2):e0004386.

62. Accelerating work to overcome the global impact of neglected tropical diseases - A roadmap for implementation. [http://www.who.int/neglected_ diseases/NTD_RoadMap_2012_Fullversion.pdf].

63. Onwujekwe O, Chima R, Okonkwo P. Economic burden of malaria illness on households versus that of all other illness episodes: a study in five malaria holo-endemic Nigerian communities. Health Policy. 2000;54(2):143-59.

64. Frick KD, Basilion EV, Hanson CL, Colchero MA. Estimating the burden and economic impact of trachomatous visual loss. Ophthalmic Epidemiol. 2003;10(2):121-32.

65. McFarland D, Menzies N, Njoumemi Z, Onwujekwe O. Study of cost per treatment with ivermectin using the CDTI strategy. African Programme for Onchocerciasis Control (APOC). 2005.

66. Muhondwa EPY. Community participation in filariasis control: the Tanzania experiment. Geneva: World Health Organization Special Programme for Research and Training in Tropical Diseases; 1983.

67. Rao CK, Sharma SP. Control of filariasis in India. J Commun Dis. 1986;18(4):276-82.

68. Ramu K, Ramaiah KD, Guyatt H, Evans D. Impact of lymphatic filariasis on the productivity of male weavers in a south Indian village. Trans R Soc Trop Med Hyg. 1996;90(6):669-70.

69. Ton TG, Mackenzie C, Molyneux DH. The burden of mental health in Iymphatic filariasis. Infect Dis Poverty. 2015;4:34.

70. Ramaiah KD, Vijay Kumar KN. Effect of lymphatic filariasis on school children. Acta Trop. 2000:76(2):197-9.

71. King CH. Health metrics for helminth infections. Acta Trop. 2015;141(Pt B):150-60.
72. Knopp S, Mohammed KA, Speich B, Hattendorf J, Khamis IS, Khamis AN, Stothard JR, Rollinson D, Marti H, Utzinger J. Albendazole and mebendazole administered alone or in combination with ivermectin against Trichuris trichiura: a randomized controlled trial. Clin Infect Dis. 2010;51(12):1420-8.

73. Truscott JE, Turner HC, Anderson RM. What impact will the achievement of the current World Health Organisation targets for anthelmintic treatment coverage in children have on the intensity of soil transmitted helminth infections? Parasit Vectors. 2015;8(1):551.

74. Turner HC, Truscott JE, Hollingsworth TD, Bettis AA, Brooker SJ, Anderson RM. Analysis of the population-level impact of co-administering ivermectin with albendazole or mebendazole for the control and elimination of Trichuris trichiura. Infect Dis Poverty. 2016; In press.

75. Turner HC, Truscott JE, Bettis AA, Shuford KV, Dunn JC, Hollingsworth TD, Brooker SJ, Anderson RM. An economic evaluation of expanding hookworm control strategies to target the whole community. Parasit Vectors. 2015;8:570.

76. Pion SD, Chesnais CB, Bopda J, Louya F, Fischer PU, Majewski AC, Weil GJ, Boussinesq M, Missamou F. The impact of two semiannual treatments with albendazole alone on lymphatic filariasis and soil-transmitted helminth infections: a community-based study in the republic of congo. Am J Trop Med Hyg. 2015;92(5):959-66.

77. Heukelbach J, Winter B, Wilcke T, Muehlen M, Albrecht S, de Oliveira FA, Kerr-Pontes LR, Liesenfeld O, Feldmeier $\mathrm{H}$. Selective mass treatment with ivermectin to control intestinal helminthiases and parasitic skin diseases in a severely affected population. Bull World Health Organ. 2004;82(8):563-71.

78. Lawrence G, Leafasia J, Sheridan J, Hills S, Wate J, Wate C, Montgomery J, Pandeya N, Purdie D. Control of scabies, skin sores and haematuria in children in the Solomon Islands: another role for ivermectin. Bull World Health Organ. 2005;83(1):34-42.

79. Boatin BA, Richards Jr FO. Control of onchocerciasis. Adv Parasitol. 2006;61:349-94.

80. Ramaiah KD, Ottesen EA. Progress and impact of 13 years of the global programme to eliminate lymphatic filariasis on reducing the burden of filarial disease. PLoS Negl Trop Dis. 2014;8(11):e3319.

81. Norman RA, Chan MS, Srividya A, Pani SP, Ramaiah KD, Vanamail P, Michael E, Das PK, Bundy DA. EPIFIL: the development of an age-structured model for describing the transmission dynamics and control of lymphatic filariasis. Epidemiol Infect. 2000;124(3):529-41.

82. Stolk WA, de Vlas SJ, Borsboom GJ, Habbema JD. LYMFASIM, a simulation model for predicting the impact of lymphatic filariasis control: quantification for African villages. Parasitology. 2008;135(13):1583-98.

83. Irvine M, Reimer L, Njenga S, Gunawardena S, Kelly-Hope L, Bockarie M, Hollingsworth T. Modelling strategies to break transmission of lymphatic filariasis - aggregation, adherence and vector competence greatly alter elimination. Parasit Vectors. 2015;8(1):547.

84. Turner HC, Walker M, French MD, Blake IM, Churcher TS, Basáñez MG. Neglected tools for neglected diseases: mathematical models in economic evaluations. Trends Parasitol. 2014;30(12):562-70.

85. Bockarie MJ, Molyneux DH. The end of lymphatic filariasis? BMJ. 2009;338:b1686.

86. van den Hout WB. The value of productivity: human-capital versus frictioncost method. Ann Rheum Dis. 2010;69 Suppl 1:i89-91.

87. Ramaiah KD, Ramu K, Guyatt H, Kumar KN, Pani SP. Direct and indirect costs of the acute form of lymphatic filariasis to households in rural areas of Tamil Nadu, south India. Trop Med Int Health. 1998;3(2):108-15.

88. O'Lorcain P, Holland CV. The public health importance of Ascaris lumbricoides. Parasitology. 2000;121(Suppl):S51-71.

89. Adams EJ, Stephenson LS, Latham MC, Kinoti SN. Physical activity and growth of Kenyan school children with hookworm, Trichuris trichiura and Ascaris lumbricoides infections are improved after treatment with albendazole. J Nutr. 1994;124(8):1199-206.

90. Stephenson LS, Latham MC, Adams EJ, Kinoti SN, Pertet A. Physical fitness, growth and appetite of Kenyan school boys with hookworm, Trichuris trichiura and Ascaris lumbricoides infections are improved four months after a single dose of albendazole. J Nutr. 1993;123(6):1036-46.

91. Nokes C, Grantham-McGregor SM, Sawyer AW, Cooper ES, Robinson BA, Bundy DA. Moderate to heavy infections of Trichuris trichiura affect cognitive function in Jamaican school children. Parasitology. 1992;104(Pt 3):539-47.

92. Crompton DW. The public health importance of hookworm disease. Parasitology. 2000;121(Suppl):S39-50.

93. Christian P, Khatry SK, West Jr KP. Antenatal anthelmintic treatment, birthweight, and infant survival in rural Nepal. Lancet. 2004;364(9438):981-3. 